\title{
The NCSBN 2019 Environmental Scan: 40th Anniversary Edition
}

\author{
National Council of State Boards of Nursing
}




\section{CONTENTS}

January $2019 \bullet$ Volume $9 \bullet$ Issue 4 Supplement

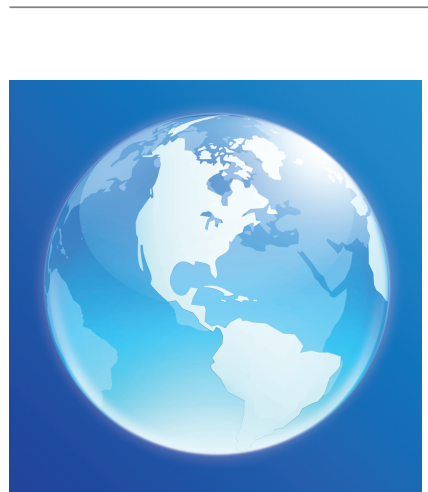

Advancing nursing excellence for public protection
The U.S. Nursing Workforce . . . . . . . . . . . . . . . . . . . S3 Registered Nurses and Licensed Practical Nurses/Licensed Vocational Nurses . . . . . . . . . . . . S3 The 2017 National Nursing Workforce Survey . . . . . . . . . . . . . . . . . . . S5 Aging of the Workforce. . . . . . . . . . . . . . . . . . . . . . . . . S5 Gender, Race, and Ethnic Diversity. . . . . . . . . . . . . . . . . . . S6 Education . . . . . . . . . . . . . . . . . . . . . . . S6

Employment Settings and Salary . . . . . . . . . . . . . . . . . . S6 Telehealth. . . . . . . . . . . . . . . . . . . . . . . . . . . . . . . Advanced Practice Registered Nurses . . . . . . . . . . . . . . . . . . . . S6 Certified Nurse Practitioners . . . . . . . . . . . . . . . . . . . . . . s6 Certified Nurse Specialists . . . . . . . . . . . . . . . . . . . . . . . . . S7 Certified Registered Nurse Anesthetists . . . . . . . . . . . . . . . . . . . . . . S7 Certified Nurse Midwives . . . . . . . . . . . . . . . . . . . . . . . . . S7 HRSA Projections for the U.S. Nursing Workforce. . . . . . . . . . . . . . . . . . S7

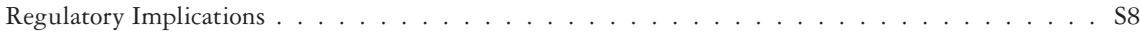

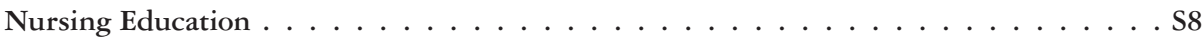

Growing Education Trends. . . . . . . . . . . . . . . . . . . . s9

New Graduates . . . . . . . . . . . . . . . . . . . . . . . . . . . . . . . . s9

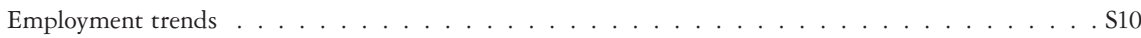

Private, Public, and For-Profit Programs . . . . . . . . . . . . . . . . . . . S11

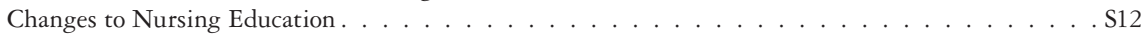

Education Program Outcomes . . . . . . . . . . . . . . . . . . . . . . . . . . S12

Clinical Experience. . . . . . . . . . . . . . . . . . . . . . . . . .

Clinical Reasoning . . . . . . . . . . . . . . . . . . . . . . . . . S13

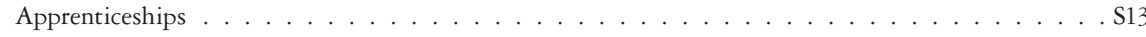

Graduate Nursing Education. . . . . . . . . . . . . . . . . . . . . . . . . . . S14

Faculty Shortage . . . . . . . . . . . . . . . . . . . . . . . . S14

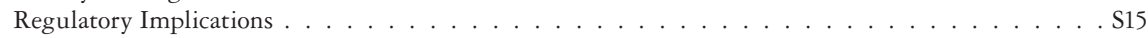

Healthcare Delivery . . . . . . . . . . . . . . . . . . . S15

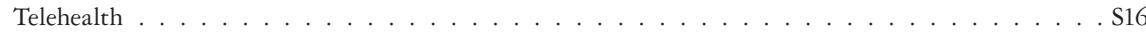

Remote Patient Monitoring . . . . . . . . . . . . . . . . . . . . . . . . . . . . . . . . . . S17

Emerging Technology . . . . . . . . . . . . . . . . . . . . . . S17

Artificial Intelligence-Assisted Diagnosis. . . . . . . . . . . . . . . . . . . . . . . . . . . . . . . . .

Personalized Technology . . . . . . . . . . . . . . . . . . . . . . . . . . . . . . S17

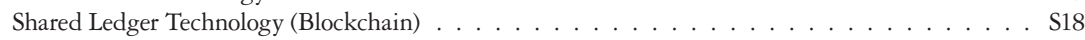

Regulatory Implications . . . . . . . . . . . . . . . . . . . . . . . . . . . . S19

Legislation and Policy Issues. . . . . . . . . . . . . . . . . . . . . . . . S19

The Nurse Licensure Compact . . . . . . . . . . . . . . . . . . . . . . . . . . . S19

The Consensus Model for APRN Licensure, Accreditation, Certification and Education: An Update. . S20

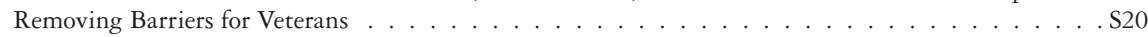

From Soldier to Nurse ......... S20

Occupational Licensure: Barrier or Public Safety Defender . . . . . . . . . . . . . . . . . . S21

State Occupational Licensure Measures . . . . . . . . . . . . . . . . . . . . . . . . . . . . S21

North Carolina State Board of Dental Examiners v. Federal Trade Commission . . . . . . . . . . S21

Federal Action Related to Licensure Reform . . . . . . . . . . . . . . . . . . . . . . . . S22

Student Loan Defaults . . . . . . . . . . . . . . . . . . . . . . . . . S22

SUPPORT for Patients and Communities Act . . . . . . . . . . . . . . . . . . . . . . . . . S23

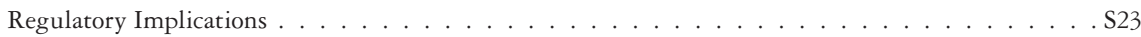

Social Issues Affecting Nursing and Regulation . . . . . . . . . . . . . . . . . . S23

Update on the Opioid Epidemic . . . . . . . . . . . . . . . . . . . . . . . . . S23

Initiatives Addressing the Opioid Epidemic . . . . . . . . . . . . . . . . . . . . S24

Medical and Recreational Marijuana Use. . . . . . . . . . . . . . . . . . . . . . . . . S25

Nurse Ambassadors . . . . . . . . . . . . . . . . . . . . . . . . . . . . . . S26

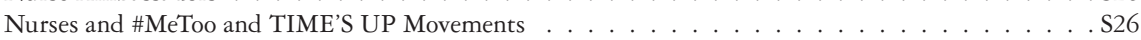

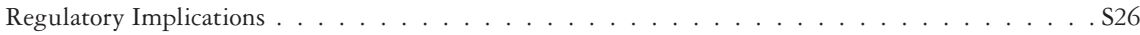

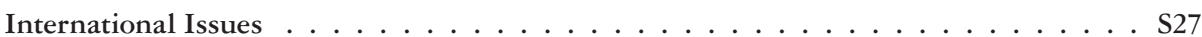

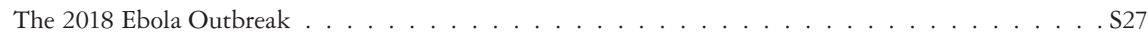

Summary and Conclusions. . . . . . . . . . . . . . . . . . . . S27

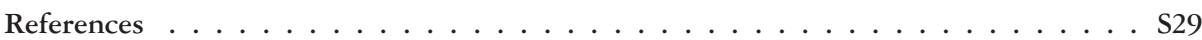

Appendix A: Board of Nursing Position and Advisory Statements . . . . . . . . . . S36

Appendix B: 2018 Center for Regulatory Excellence Research Grants. . . . . . . . . . . S40 


\section{The NCSBN 2019 Environmental Scan: 40th Anniversary Edition}

$\mathrm{I}$ n 2018, the National Council of State Boards of Nursing (NCSBN) commemorated 40 years since its founding in 1978. This milestone was more than just an opportunity to celebrate, it was an opportunity to measure the impact, outcomes, and progress made as an organization. It was also an opportune time to determine the organization's influence and effectiveness, and reflect on the safety of nursing care and the daily vigilance of boards of nursing (BONs).

In its mission to assist BONs, NCSBN publishes an annual environmental scan to help BONs strategically plan, anticipate, and prepare for new challenges on the horizon. The scan describes the state of the workforce, nursing education, healthcare delivery, technological advancements, and policy and legislation. It also describes social, emerging regulatory, and international issues impacting regulators and summarizes the actions of BONs around the country.

This environmental scan commemorates 40 years of NCSBN's work with BONs. Glimpses of the past are scattered throughout to remind us of the regulatory environment in 1978 and how much nursing and healthcare have changed, and stayed the same, since then.

\section{The U.S. Nursing Workforce}

\section{Registered Nurses and Licensed Practical Nurses/Licensed Vocational Nurses}

It was a different workforce 40 years ago. In 1978, there were approximately 1,112,000 registered nurses (RNs) and 509 employed RNs per 100,000 population (U.S. Department of Health and Human Services, 1980), which is well below the 2018 figures of nearly 4 million RNs and 785 employed RNs per 100,000 population. There were approximately 402,000 licensed practical nurses/licensed vocational nurses (LPNs/LVNs), which is also below the 2018 figure of 700,000 LPNs/LVNs, but the ratio of 184 employed LPNs per 100,000 population is comparable to the present ratio of 187 employed LPNs/LVNs per 100,000 population.

The RN workforce was 3.3\% male in 1978 compared with 9.1\% in 2017. In 1978, 11.7\% of the RN workforce was comprised of racial minorities (U.S. Census Bureau, 1979); while in 2017, 19.3\% of the RN workforce are racial minorities.

The makeup of the $R N$ workforce was different in other ways 40 years ago as well. For example, it was younger. Around the turn of the millennium, Buerbaus, Staiger, and Auerbach noted that over the past 15 years, the age of the average RN increased from 37.4 years to 41.9 years and the number of nurses under 30 years of age decreased from nearly 33\% of the workforce to 12\% (Buerhaus, Staiger, E Auerbach, 2000). The reason was multifaceted, including that it was simply a smaller generation of students entering college in general and the widening of culturally acceptable jobs for women over those decades. Most notable; however, was the sudden surge of associate degree in nursing (ADN) programs beginning around 1978 that made nursing a viable second career for older, nontraditional students. By 2000, nearly 60\% of new graduates were from associate programs.

As of November 20, 2018, there were precisely 3,992,453 RNs and 927,039 LPNs/LVNs in the United States according to NCSBN's National Nursing Database (National Council of State Boards of Nursing [NCSBN], 2018d). However, the most recent Occupational Employment Statistics data from May 2017 indicate 2,906,840 RNs and 702,700 LPNs/LVNs were employed in the United States (data excluded Michigan) (U.S. Bureau of Labor Statistics [BLS], 2018a; 2018b). Figures 1 and 2 illustrate the growing RN and LPN/LVN employment, which is holding steady. 


\section{FIGURE 1}

\section{Numbers of Employed RNs and LPNs/LVNs in the United States}
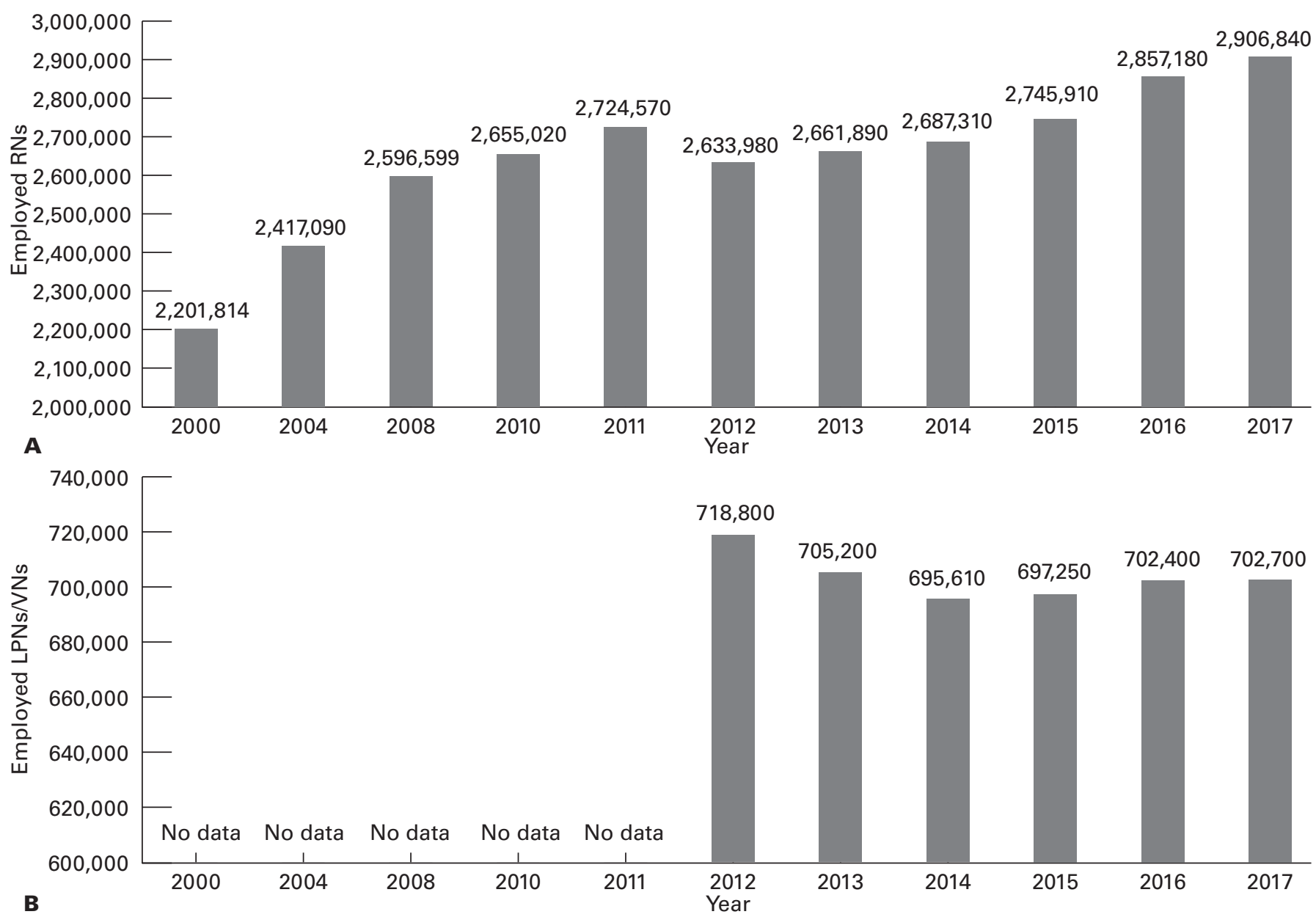

Note. The 2010-2017 statistics are from the semiannual Occupational Employment Statistics (OES) survey published by the U.S. Bureau of Labor Statistics (2018). The 2000, 2004, and 2008 are from the U.S. Department of Health and Human Services Health Resources Services Administration (HRSA)'s National Sample Survey of Registered Nurses (2010).

The number of employed RNs per population in each state varies widely across the country, from slightly over 600 RNs per 100,000 population in Utah to just under 1,400 RNs per 100,000 population in the District of Columbia (Figure 2) (BLS, 2018a; 2018b; U.S. Census Bureau, 2018a). Other states with approximately 600 RNs per 100,000 population are Oklahoma, Nevada, and Alaska. Conversely, states like South Dakota (1,235 per 100,000 population), Delaware (1,078 per 100,000 population), and Massachusetts (1,067 per 100,000 population) have the highest ratios of employed RNs per population. The ratio of employed LPNs/LVNs is between 45 and 60 per 100,000 population in Alaska, Utah, and Oregon and nearly 400 per 100,000 population in Louisiana and Arkansas. 


\section{FIGURE 2}

\section{Number of Employed RNs and LPNs/LVNs per 100,000 Population}

RNs

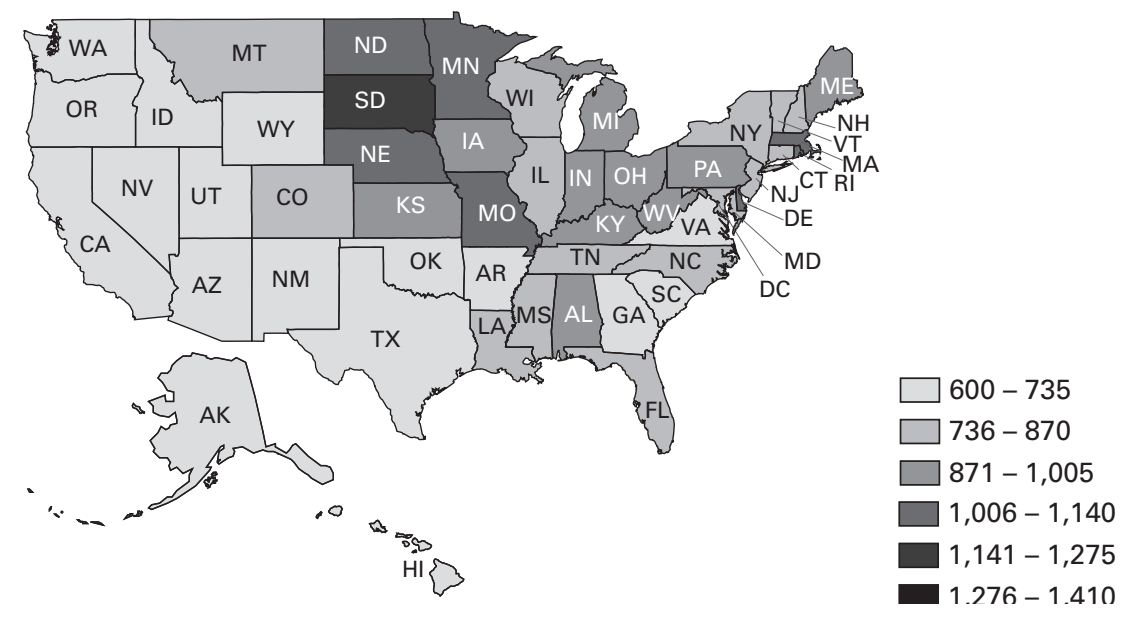

LPNs/LVNs

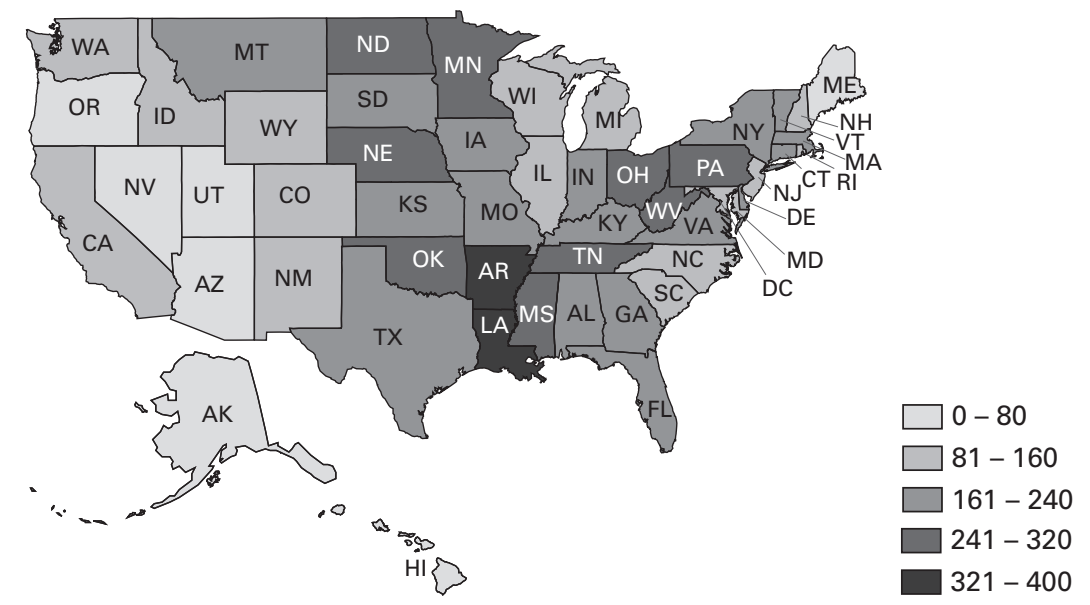

Note. Employed RNs and LPNs/LVNs per 100,000 people by state as of May 2017.

Source: U.S. Bureau of Labor Statistics, 2018a; 2018b; U.S. Census Bureau, 2018a.

Figure 2 gives a quick state-level snapshot of employed nurses; however, there are regional differences within each state not shown that could be different from the overall state-level view. These regional differences within states are often the main concern for individuals involved in studying and monitoring the nursing workforce. For instance, California has one of the lowest employed nurse-to-population ratios; however, within the state, city centers such as San Francisco may have very high nurse-to-population ratios, whereas rural areas of the state may very low nurse-to-population ratios. State-specific regional nurse employment data are available for download from the U.S. Bureau of Labor Statistics (BLS).

\section{The 2017 National Nursing Workforce Survey}

Since 2013, NCSBN and The National Forum of State Nursing Workforce Centers (Forum) have partnered every two years to conduct a national sample survey using the Forum's Nurse Supply Minimum Data Set, a standardized survey tool designed to collect workforce data. The 2017 survey results were released in the fall of 2018 (Smiley et. al., 2018). Important findings are summarized in this report below.

\section{Aging of the Workforce}

The average age of RNs was 50 years in 2017, which is consistent with the previous survey findings. In 2015, $12.4 \%$ of the RN respondents were 65 years of age or older, compared with $14.6 \%$ in the 2017 study, which indicates a slow but steady growth of RNs who may be heading for retirement. The average age of LPNs/LVNs in 2017 (52 years) was a year older than in 2015. The percentage of LPNs 65 years of age and older increased from 9.9\% in 2015 to 13.2\% in 2017 (Smiley et. al., 2018). 


\section{Gender, Race, and Ethnic Diversity}

The percentage of male RNs (9.1\%) in the 2017 workforce increased by 1.1 from the 2015 study (8.0\%) and 2.5 percentage points from the 2013 study (6.6\%). Additionally, 19.3\% of the RN respondents were minorities, including: (a) Asian (7.7\%), (b) Black/African American (6.2\%), (c) Hispanic or Latino (5.0\%), (d) other (2.8\%), and (e) two or more races (1.8\%). (Smiley et. al., 2018) The percentage of nurses who identify as Asian in the 2017 study exceeds the 5.7\% represented in the U.S. population and the percentage of nurses who identify as Black/African American falls below the 13.3\% in the U.S. population (Smiley et. al., 2018; U.S. Census Bureau, 2018b).

The LPN/LVN workforce remains relatively unchanged in terms of gender diversity between 2015 and 2017. The percentage of males in the LPN/LVN workforce increased from $7.5 \%$ to $7.8 \%$ between the two studies. LPNs/LVNs are more racially and ethnically diverse than their RN counterparts. Approximately $29 \%$ of LPNs/LVNs were racial minorities with the largest reporting minority group being Black/African Americans (18.1\%) (Smiley et. al., 2018).

\section{Education}

The trend toward a higher percentage of respondents pursuing a Bachelor of Science in nursing (BSN) degree as their initial nursing education continued in 2017. Approximately $42 \%$ of RNs reported the BSN as the degree that qualified them for their first U.S. nursing license, which reflects a $2.7 \%$ increase compared with 2015 (39.0\%) and a 6.2\% increase compared with 2013 (35.5\%). In terms of graduate education, the number of RNs with a master's degree in nursing has increased from $13.8 \%$ in 2013 to $17.1 \%$ in 2017 . Although small in terms of percentage, $1.2 \%$ of responding RNs reported having a Doctorate in Nursing Practice (DNP) as their highest level of nursing education, which is double the percent of nurses who reported having a DNP in 2015 (Smiley et. al., 2018).

By comparison, $83 \%$ of LPNs/LVNs indicated their entry-level qualification for their first U.S. nursing license was a vocational/ practical certificate. Of those, more than $75 \%$ did not pursue a higher level of nursing education (Smiley et. al., 2018).

\section{Employment Settings and Salary}

Work settings are changing for nurses as patient care is no longer confined to the walls of a healthcare facility. Hospitals were the primary employment setting for $55.7 \%$ of RNs, an increase from $54.4 \%$ in 2015 , but less than the $56.5 \%$ reported in 2013 . Ambulatory care settings (9.4\%) were the second most frequently selected employment setting reported by RNs, followed by nursing home/extended care (4.8\%) and home health (4.3\%) (Smiley et. al., 2018).

The median pre-tax annual earnings for RNs increased from $\$ 60,000$ in 2015 to $\$ 63,000$ in 2017 . In the 2017 study, the number of responding RNs making between $\$ 80,000$ and $\$ 100,000$ increased by $1.6 \%$ and those making more than $\$ 100,000$ increased by nearly $4 \%$ (Smiley et. al., 2018).

Nursing home/extended care was the most common work setting for LPNs/LVNs (31.6\%), followed by home health settings (15.0\%) and hospitals (9.0\%). These findings are consistent with results from the 2015 survey (Smiley et. al., 2018).

The median pre-tax annual earnings for LPNs/LVNs increased from $\$ 38,000$ in 2015 to $\$ 40,000$ in 2017 (Smiley et. al., 2018).

\section{Telehealth}

Over half (54.1\%) of responding RNs provided nurse services using telehealth in 2017 . Of those, $45.7 \%$ provided telehealth across a state border compared with $39.4 \%$ in 2015 . Additionally, $11.1 \%$ of RNs reported providing remote services to patients/clients across national borders, which is a $3.4 \%$ increase from 2015 (Smiley et. al., 2018).

LPNs/LVNs provided nursing services using telehealth technologies in equal proportions to RNs (54.1\%). Of those providing telehealth services, $44.1 \%$ did so across state borders, which is a $10.3 \%$ increase from 2015 (Smiley et. al., 2018).

\section{Advanced Practice Registered Nurses Certified Nurse Practitioners}

The 2017 survey found the median age of certified nurse practitioners (CNPs) is 51 years of age, which is consistent with the 2015 survey. In 2015, 9.4\% of the CNP respondents were 65 years of age or older compared to $12.3 \%$ in the current study, which indicates a steady growth of the CNP population heading for retirement. The percentage of male CNPs $(7.2 \%)$ in the 2017 workforce was slightly less than in the 2015 workforce (7.5\%) (Smiley et. al., 2018).

Ambulatory care (27.5\%) and hospitals (26.5\%) were the primary employment settings for CNPs, but less than the $30.3 \%$ reported for ambulatory care and $28.6 \%$ reported for hospitals in 2015 . Approximately $8 \%$ of CNPs reported community health as their primary work setting, which is an increase from the $6.5 \%$ reported in 2015 . The median pre-tax annual earnings for CNPs increased from $\$ 88,000$ in 2015 to $\$ 96,000$ in 2017 . Responding CNPs making more than $\$ 100,000$ increased from $35.6 \%$ in 2015 to $50.7 \%$ in 2017 (Smiley et. al., 2018). 
A majority (69.6\%) of responding CNPs provided telehealth. In the 2017 study, $43.5 \%$ of CNPs provided telehealth across a state border compared with $41.3 \%$ in 2015 . Additionally, 9.3\% reported providing remote services to patients/clients across national borders, which is $1.1 \%$ increase from 2015 (8.2\%). The percent of CNPs communicating via a telephone substantially increased from 60.0\% in 2015 to $91.9 \%$ in 2017 (Smiley et. al., 2018).

\section{Certified Nurse Specialists}

The median age of certified nurse specialists (CNSs) in 2017 was 60 years, which is a year older than the 59 years in 2015. In 2015, $20.0 \%$ of CNS respondents were 65 years of age or older compared with $27.6 \%$ in 2017, which indicates a rapid growth of the CNS population heading for retirement. The percentage of male CNSs (7.2\%) in the 2017 workforce was noticeably larger than in the 2015 workforce (4.6\%) (Smiley et. al., 2018).

Hospitals (47.4\%) and ambulatory care (10.9\%) were the primary employment settings for CNSs in 2017, which is similar to the reported percentages for hospitals (44\%) and ambulatory care (11.3\%) in 2015. But the $6.5 \%$ of CNSs who reported a school of nursing as their primary work setting in 2017 was a significant decrease from the $18.7 \%$ reported in 2015. The median pre-tax annual earnings for CNSs declined from $\$ 85,400$ in 2015 to $\$ 80,000$ in 2017 . Responding CNSs making more than $\$ 100,000$ declined from $37.3 \%$ in 2015 to $34.3 \%$ in 2017 (Smiley et. al., 2018).

A majority (64.0\%) of responding CNSs provided telehealth. In the 2017 study, 55.8\% provided telehealth across a state border compared with $46.4 \%$ in 2015 . Additionally, $16.0 \%$ reported providing remote services to patients/clients across national borders, which is a $3.5 \%$ increase from 2015 (12.5\%). The percent of CNPs communicating via a telephone substantially increased from 54.1\% in 2015 to $89.5 \%$ in 2017 (Smiley et. al., 2018).

\section{Certified Registered Nurse Anesthetists}

The median age of certified registered nurse anesthetists (CRNAs) was 52 years in 2017, which is a year older than in 2015. In 2015, $11.0 \%$ of the CRNA respondents were 65 years of age or older compared with $12.5 \%$ in 2017 , which indicates a slow but steady growth of the CRNA population heading for retirement. The percentage of male CRNAs (36.0\%) in the 2017 workforce was larger than in the 2015 workforce (34.1\%) (Smiley et. al., 2018).

Hospitals (84.7\%) and ambulatory care (12.5\%) were the primary employment settings for CRNAs, which is similar to the percentages reported for hospitals (81.8\%) and for ambulatory care (12.0\%) in 2015. The median pre-tax annual earnings for CRNAs increased from $\$ 152,000$ in 2015 to $\$ 168,000$ in 2017 . Responding CRNAs making more than $\$ 100,000$ increased from $86.0 \%$ in 2015 to $87.4 \%$ in 2017 (Smiley et. al., 2018).

Well under half (30.5\%) of responding CRNAs provided telehealth. In the 2017 study, $23.1 \%$ provided telehealth across a state border compared with $29.1 \%$ in 2015 . Additionally, $3.6 \%$ reported providing remote services to patients/clients across national borders, which is a $4.1 \%$ decrease from $2015(7.7 \%)$ (Smiley et. al., 2018).

\section{Certified Nurse Midwives}

The median age of Certified Nurse Midwives (CNM) was 57 years in 2017, which is two years older than in 2015. In 2015, 13.8\% of the CNM respondents were 65 years of age or older compared with $15.8 \%$ in 20167, which indicates a steady growth of the CNM population heading for retirement. The percentage of male CNM (0.0\%) in the 2017 workforce was noticeably smaller than in the 2015 workforce (5.4\%) (Smiley et. al., 2018).

Hospitals (45.5\%) and ambulatory care (18.3\%) were the primary employment settings for CNM, which increased from the percentages reported for hospitals (43.0\%) and ambulatory care (13.6\%) in 2015. The $10.3 \%$ of CNM who reported their primary work setting to be in community health in 2017 was a decrease from the $11.2 \%$ reported in 2015 . The median pre-tax annual earnings for CNWs increased from $\$ 85,500$ in 2015 to $\$ 90,000$ in 2017. Responding CNM making more than $\$ 100,000$ increased from $32.4 \%$ in 2015 to $44.5 \%$ in 2017 (Smiley et. al., 2018).

A majority (70.4\%) of responding CNM provided telehealth. In the 2017 study, $51.4 \%$ provided telehealth across a state border compared with $35.3 \%$ in 2015. Additionally, $6.9 \%$ reported providing remote services to patients/clients across national borders, which is similar to 2015 (6.6\%). The percent of CNM communicating via a telephone substantially increased from $62.5 \%$ in 2015 to $94.9 \%$ in 2017 (Smiley et. al., 2018).

\section{HRSA Projections for the U.S. Nursing Workforce}

In 2017, the Health Resources and Services Administration (HRSA) released national projections for the U.S. nursing workforce through 2030 (Health Resources and Services Administration [HRSA], 2017). The estimates suggest the United States will have a sufficient supply of RNs to meet the projected demand for RN services in 2030, although considerable variability at regional and local levels could be present. For LPNs/LVNs, the estimates suggest patient demand in 2030 could slightly outpace LPN/LVN supply at the national level with a risk of considerable variability at regional and local levels. 
HRSA also explored projected demand in long-term services and supports (LTSS) for RNs and LPNs (HRSA, 2018). The study's baseline model projected the demand for RNs working in LTSS will increase by approximately $46 \%$ from 438,600 full-time employees (FTEs) in 2015 to 638,800 FTEs in 2030. Likewise, the demand for LPNs working in LTSS will increase by approximately $46 \%$ from 364,200 FTEs in 2015 to 532,900 FTEs in 2030. For RNs, the states projected to have the highest demand increases are Colorado (76\%), Utah (74\%), New Mexico (72\%), Arizona (72\%), California (71\%), and Texas (71\%). For LPNs, the states projected to have the highest demand increases are Colorado (78\%), Utah (75\%), New Mexico (74\%), Arizona (73\%), California (72\%), and Texas (72\%).

At the state level, Louisiana and Utah dedicated funding to programs that help meet current and future healthcare workforce demands (H.B. 144, La. 2018; S.B. 147, Utah. 2018). Arizona enacted a bill in 2018 that facilitates data collection for ensuring a sufficient healthcare workforce (H.B. 2197, Ariz. 2018).

\section{Regulatory Implications}

- According to the data, nearly one third of nurses with active RN licenses are not employed in nursing. Should these nurses choose at any point to return to the workforce, are there mechanisms in place to ensure that they return to practice safely? Given the continuing regional shortages in the nursing workforce, this question is particularly pertinent, as retired nurses may be enticed back into the workforce. This situation suggests a possible future need for a standardized return to practice requirements.

- The trend for LPN/LVN graduates has been decreasing since 2012. What will be the impact on long-term care and facilities that depend on LPNs/LVNs as the mainstay of their workforce? Will the retirement threshold for LPNs/LVNs change? Will there be an increased reliance and use of unlicensed assistive personnel (UAP) and if so, what might this mean for safety and quality of care? As of May 2017, there were over 54,000 community health workers in the United States, as well as over 800,000 home health aides and more than 1.4 million nursing assistants (BLS, 2018c; 2018d; 2018e). Through 2026, the BLS projects faster than average job growth for each of these UAP roles, with nursing assistants realizing $11 \%$ growth, community health workers relaizing $16 \%$ growth, and home health aide employment growing by an astonishing 41\% (BLS, 2018f; 2018g; 2018h). Will these roles gradually expand to fill the void left by a slowly shrinking LPN/LVN workforce? One possible solution would be the creation of an articulated system by which UAPs can transition into more highly trained roles, such as LPNs/LVNs and RNs.

- To assist with monitoring of these trends, NCSBN continues to build its workforce database with new BONs contributing data each year. There are 25 BONs participating in NCSBN's workforce database.

- Currently, there is not an accurate count of advanced practice registered nurses (APRNs). This is complicated by the fact that not all states use the same titles and not all states issue licenses; however, steady improvement continues. Each year more states are legislating changes to build conformity with the APRN Consensus Model and BONs are increasingly entering APRN data into NCSBN's Nursys ${ }^{\circledast}$ database. There are $24 \mathrm{BONs}$ contributing APRN data into Nursys. These are major steps towards having the exact numbers of APRNs in the National Nursing Database that already exists for RNs and LPNs/LVNs.

- As CNPs indicate increased provision of care via telehealth, it falls to educators to ensure assessment and diagnosis via telehealth is included in CNP curriculum via clinical experiences or simulation. More analyses on the U.S. workforce will be performed and published based on the 2017 National Workforce Study data. The next survey will be conducted in the winter of 2019.

\section{Nursing Education}

Nursing education looked different 40 years ago when BSN programs graduated less than a quarter of new graduates and diploma programs provided over a third of the new graduate nursing workforce (Choinski, Hamer, Hamm, Macdonald, E Nelson, 1978). ADN programs began as seven pilot programs in 1952 and by 2002 graduated nearly 60\% of new RNs (Mabaffey, 2002). Then, as is the case today, the controversial question of whether the BSN should be the entry into the profession lingered, with opposed educators at the time arguing that BSN programs alone could not sufficiently meet the demands of workforce projections (Choinski et al, 1978).

Perhaps one of the most long standing and controversial issues in nursing has been entry into practice. While ADN programs flourished 40 years ago, the debate over $\mathrm{RN}$ education requirements existed then as it does today.

Beginning in 2008, the American Nurses Association (ANA) voted overwhelmingly to support state initiatives requiring nurses to obtain a BSN in their first 10 years of practice, a policy initiative commonly referred to as "the BSN in 10." (Trossman, 2008). New York's and New Jersey's state nurses' associations brought the 2008 resolution to the forefront and nearly a decade later, New York enacted BSN in 10 legislation (Mensik, 2017) through New York Senate Bill 6768, which became law on December 18, 2017 (S.B. 6768, N.Y. 2017). The bill requires nurses to obtain a BSN degree within ten years of initial licensure in the state (S.B. 6768, N.Y. 2017). Nurses licensed prior to the enactment date and students currently enrolled or pending acceptance into associate or diploma nursing programs are exempt (S.B. 6768, N.Y. 2017). Ann Harrington, Executive Director of the New York Organization of Nursing Executives and Leaders expressed support for the bill saying:

As nurse leaders, we support advancing registered nurse education to improve the health of our communities throughout the state. Residents will be better cared for in their homes, expensive hospitalizations can be avoided, and — as validated by research — health outcomes will improve. (Thew, 2018). S8 Journal of Nursing Regulation 
New York's enactment may spur others to consider the legislation and may aid efforts in states that have introduced BSN in 10 legislation in the past, such as New Jersey and Rhode Island (Nightingale College, 2018).

\section{Growing Education Trends}

Across the United States, there is an overall growing trend among students entering nursing to acquire a BSN. Data derived from ADN and BSN first-time NCLEX takers from 2008 to 2017 indicate that while there were more ADN graduates during that time, the number of BSN graduates increased at a faster rate (Figure 3). By 2017 the two groups were almost equal (79,511 for ADN and 75,944 for BSN). In a projection model from 2016 to 2026 analyzing secondary data, Spetz (2018) suggests that based on current patterns of entry-level BSN graduates and graduates of RN to BSN programs, $66 \%$ of RNs with a BSN are projected by 2025 . This is well below the $80 \%$ by 2020 the Future of Nursing initiative targeted; however, the data reflect the concerted effort of many working toward that goal (Institute of Medicine [IOM], 2011). Strategies to improve this trajectory include employer assistance, employers requiring a BSN within a specified amount of time, and employer policies that encourage pursuit of the BSN, including community colleges offering baccalaureate degrees or collaboration between universities and community colleges (Spetz, 2018).

FIGURE 3

\section{0-Year Trend of ADN and BSN First-time NCLEX Takers}

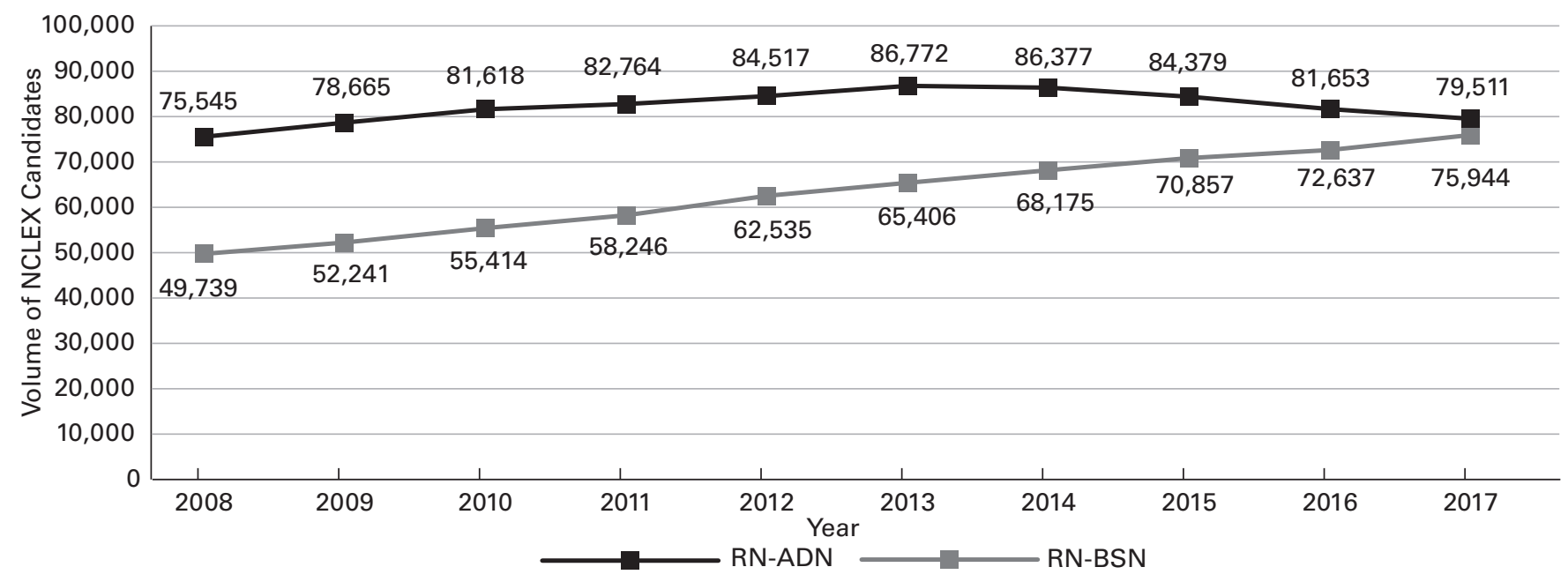

Despite the growing number of BSN-educated nurses, recent data suggest a reluctance among ADN and diploma students to pursue advanced education. In 2017 and 2018, as compared with 2014, there was a slight downward trend in ADN and diploma students' intentions of pursuing advanced education (Feeg \& Mancino, 2018a; Feeg \& Mancino, 2018b). This could be, in part, due to increases in student debt (Feeg \& Mancino, 2018a). However, 2018 data from the National Student Nurse Association (NSNA) (Feeg \& Mancino, 2018b) illustrate a positive trend related to ADN and diploma students advancing their education. In $2018,35 \%$ of ADN and diploma students were enrolled in education programs, as compared to $24 \%$ in 2017.

\section{New Graduates}

Figure 4 illustrates the 10-year trend in RN and LPN first-time NCLEX takers, which can be used as a proxy for new graduates entering nursing. For RNs, there was a steady increase from 2008 to 2014 followed by a plateau. The number of new nurses entering the profession has remained constant since 2014. For LPNs/LVNs; however, there has been a steady decline in numbers since 2011 (Smiley et. al., 2018). 


\section{FIGURE 4}

\section{0-year Trend of RN and LPN/LVN First-time NCLEX Takers}

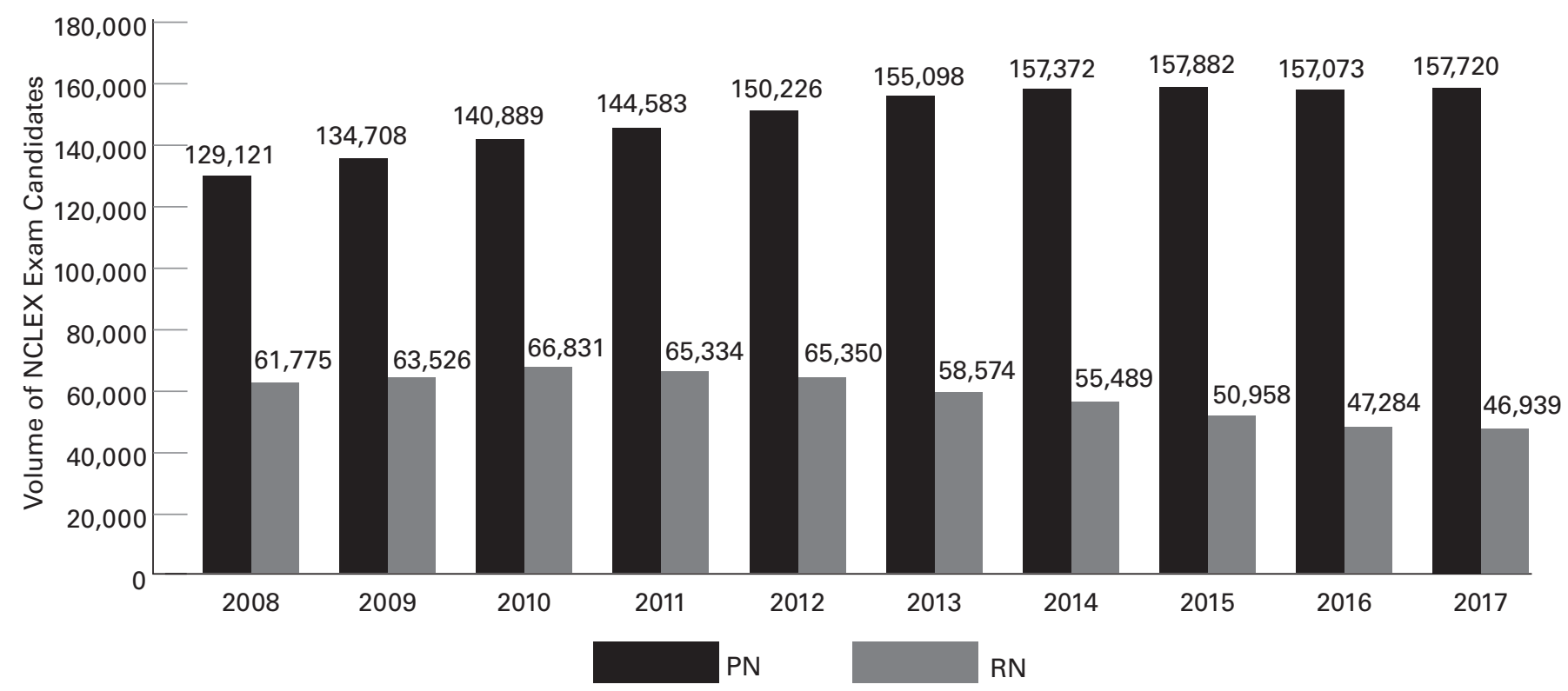

\section{Employment trends}

After the Future of Nursing report called for $80 \%$ of nurses to have baccalaureate degrees by 2020 (IOM, 2011), some employers have preferred to hire baccalaureate graduates over associate degree graduates. Similarly, hospitals with Magnet designations also preferred to hire new graduates with baccalaureate degrees. Employment improved in all levels of education (associate degree, baccalaureate degree and accelerated baccalaureate degree) since last year; however, ADN hires continue to lag baccalaureate hires at a statistically significant rate $(\mathrm{Chi} \mathrm{Sq}=20.27 ; p<.001)$. Interestingly, there was an increase in hiring of graduates with an accelerated baccalaureate degree from 2017 to 2018 (Figure 5) (Feeg \& Mancino, 2018a; 2018b).

\section{FIGURE 5}

\section{Employment by Level of New Graduate Education}

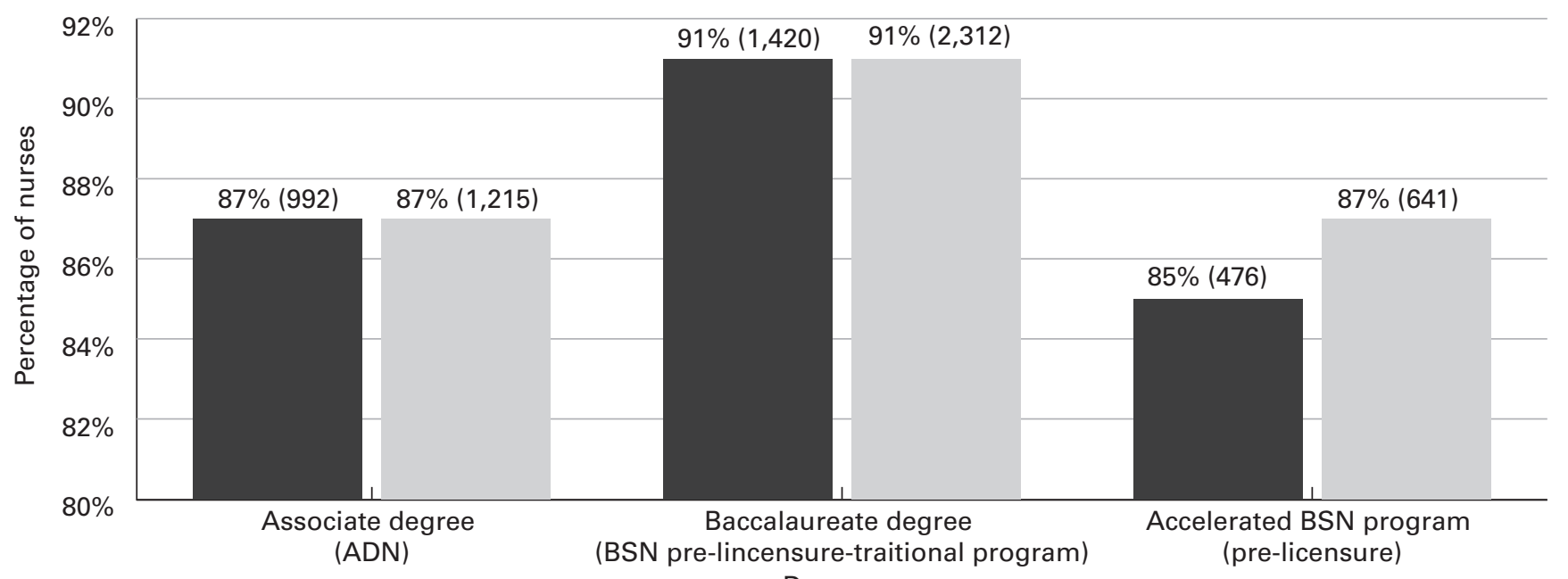

Degrees

Additional survey data describing new graduate employment is collected by the NSNA (Feeg \& Mancino, 2018a), which has been studying new graduate employment trends since 2009 (Figure 6). In 2009, during the fallout from the 2008 recession, NSNA 
reported (Mancino, 2009) 41\% of associate degree, diploma, and baccalaureate degree graduates $(n=1,404)$ surveyed indicated there were no jobs for new graduates of nursing programs. Today, the employment picture for new graduates is much brighter. Over the past year, new graduate employment remains relatively stable $(2017=88.1 \% ; 2018=88.96 \%)(\mathrm{n}=4,897)$. Regions of the country have had similar trends over the past 9 years, with the West and Northeast lagging behind the Central and South; however, that disparity has decreased since 2015 (Feeg \& Mancino, 2018a).

\section{FIGURE 6}

\section{New Graduate Employment by Regions}

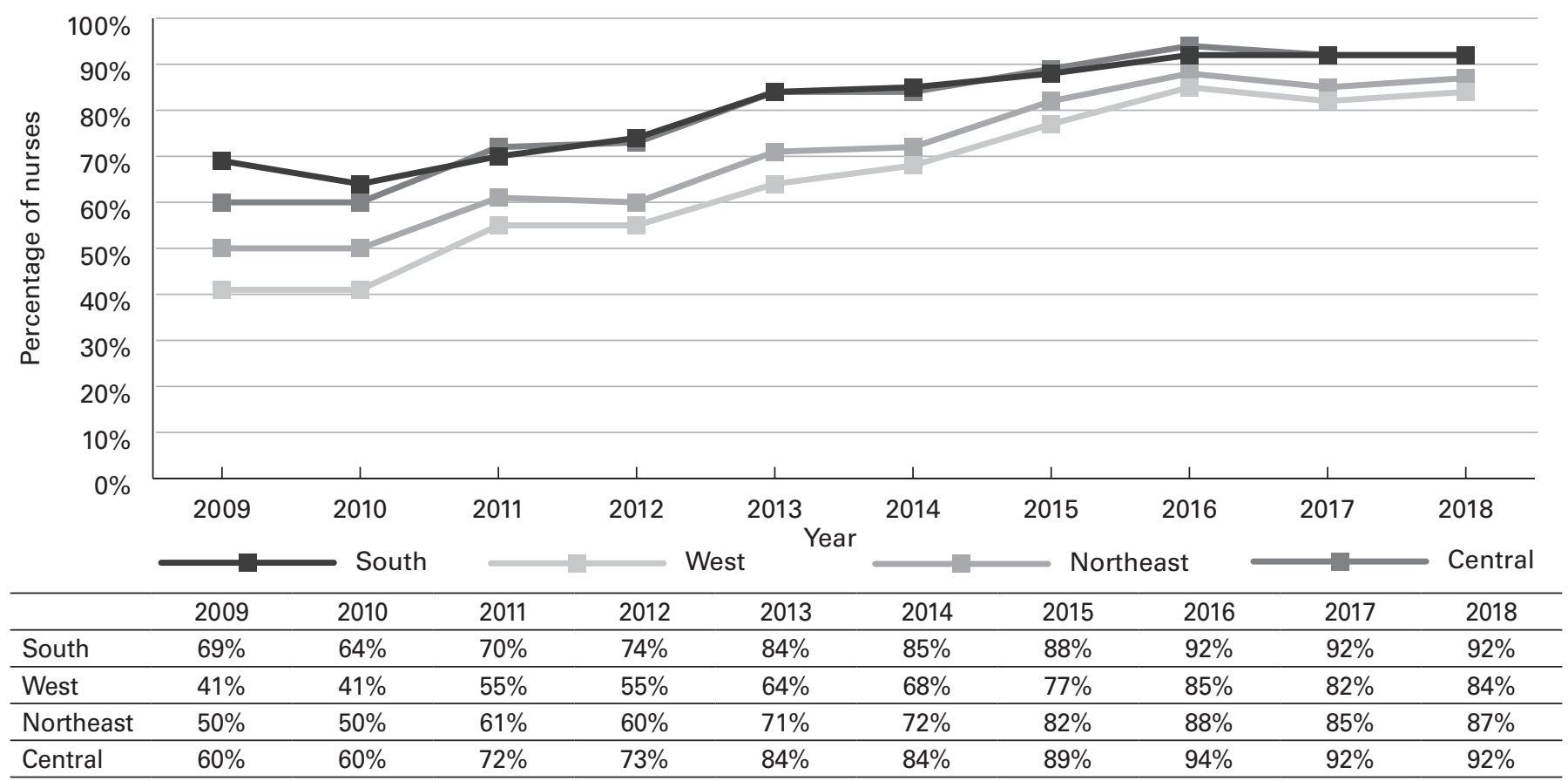

Note. The data are from NSNA's interim report and not the final report. The survey was conducted in September 2018 and continues to receive responses at time of press.

\section{Private, Public, and For-Profit Programs}

According to Feeg \& Mancino (2018a), there are marked differences in the employment rate of graduates from different types of programs with for-profit schools having a lower employment rate. However, in 2018, that difference markedly decreased, though it is still slightly lower than public or private schools (Figure 7)

\section{FIGURE 7}

\section{Employment Rate of Public, Private, and For-Profit Program Graduates}

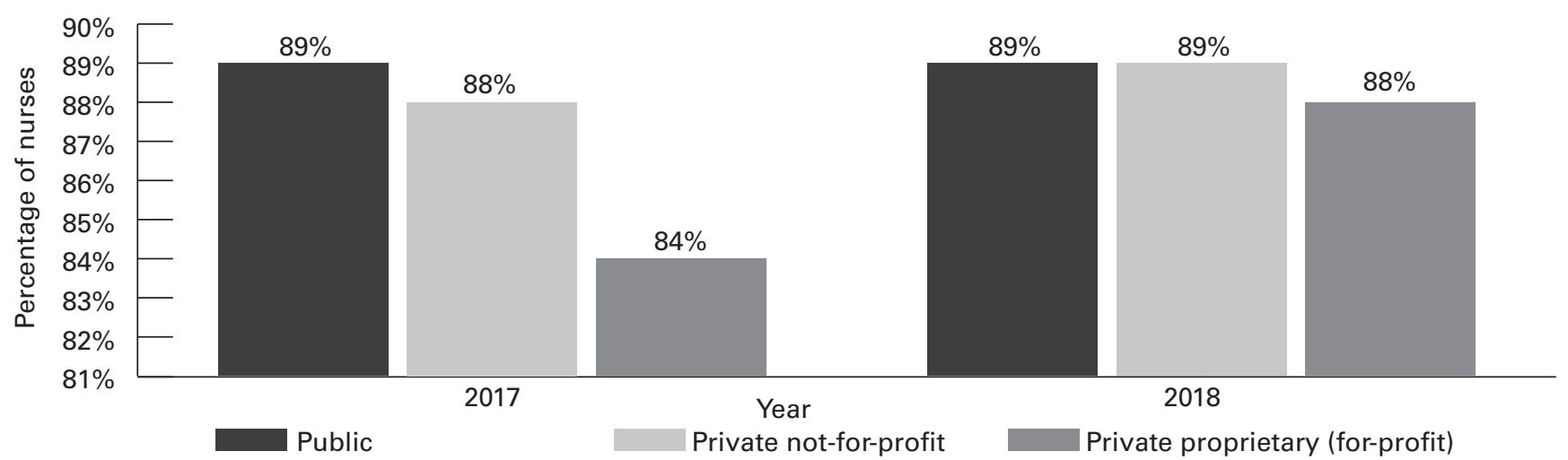




\section{Changes to Nursing Education}

Healthcare and society in general are experiencing many technological changes and the nursing education community needs to prepare for the "seismic shift" in nursing education (Murray, 2018). Murray asks how this disruptive innovation of technology will affect the way we teach nursing. She also anticipates that many of our established ways of teaching will "topple" as advances in computer technologies, virtual reality, use of the HoloPatient (holographic capture technology to simulate real-world conditions so students can assess, diagnose, and interact with patients) (Microsoft, 2018), and data literacy become more important in nursing education (Murray, 2018).

\section{Education Program Outcomes}

Educators 40 years ago were in search of both evidence-based metrics of a successful program and predictors of success on licensure examinations. Notably, in the latter case, the literature of the time focused on student performance on other standardized tests, which were used as predictor examinations (Outtz, 1979).

One of the movements in nursing education, and higher education in general, is to have a better understanding of metrics and outcomes in nursing education. At a medical education workshop sponsored by the National Academies of Sciences, Engineering and Medicine (2018), participants agreed the focus must shift from inputs (e.g., curriculum, faculty, student admissions) to student outcomes. While acknowledging it is difficult, it is also important to gather evidence related to patient outcomes. Martin, Zindel \& Nass (2018) recommend piloting innovative ways of measuring outcomes and metrics in education programs for physicians. Similarly, NCSBN is conducting studies to validate a legally defensible model for BONs to approve nursing programs (Spector, Hooper, Silvestre \& Hong, 2018).

Two recent national nursing education studies using NCLEX first-time pass rates as an outcome found a statistical difference in pass rates when a program is larger and public (Odom-Maryon, Bailey \& Amiri, 2018; Pittman, 2018 in press). This may seem surprising, until the nature of large public universities is considered. For example, there may be more resources, access to direct patient care, and rich clinical experiences. When approving nursing programs, BONs reported better outcomes when a greater percentage of faculty are full-time and BONs have policies or rules that cite full-time/part-time faculty ratios (NCSBN, 2017). However, Odom-Maryon, Bailey, and Amiri's (2018) national study presents evidence to support higher percentages of full-time faculty contributing to improved student outcomes.

Similarly, BONs experienced difficulties with programs that use standardized tests for program progression or for graduation. Five BONs (AL, NV, NC, OR and TX) prohibit high-stakes testing to prevent students from completing the program when all other requirements have been met. Three BONs (NC, OR and TX) prohibit use of standardized examinations to be used as a sole measure for progression through the curriculum (Hunsicker \& Chitwood, 2018). While positive results of using standardized examinations in education include providing practice for taking licensure examinations and increasing their test taking confidence, the negative consequences relate to faculty and student stress, which affects coping and their ability to learn. Faculty stress, interestingly, was related to the mismatch between student grades and the standardized testing scores. Some suggest standardized tests may evaluate the students' abilities to test but not their knowledge level. Students have filed complaints and lawsuits with BONs when standardized tests prevent them from graduating (Hunsicker \& Chitwood, 2018). Faculty may wish to weigh these considerations when contemplating the use of standardized testing with their students in the future. The National League for Nursing (NLN) and NCSBN have provided some direction on how nursing programs might use standardized tests (Spector \& Alexander, 2006; National League for Nursing [NLN], 2012)

\section{Clinical Experience}

Forty years ago, faculty had the same problems evaluating students clinically as they do today. Faculty had difficulty grading student's clinical performance, using a vague tool that rated students as 'always', 'usually', 'sometimes', or 'never' meeting standards (Oermann, 2018).

The same clinical experience grading ambiguities that plagued educators 40 years ago plague contemporary educators. Today, faculty struggle to evaluate student clinical performance, often resorting to grade inflation so there is no variance in grading. This may result in programs graduating nurses who are less clinically competent than their records suggest. In their study of grade inflation, Seldomridge and Walsh (2018) make the following recommendations for increasing the precision of clinical experience grading: a) develop clear, criterion-referenced standards, (b) ensure faculty development to reduce rater error, (c) standardize the experiences (e.g., clinical laboratories, simulations) as much as possible, and (d) incorporate repetition and constancy, such as consistent clinical experiences and faculty and focusing on common health issues. Enhancing the precision in grading clinical experiences will allow educators to truly evaluate students and to step in when students are borderline or falling below standards.

Because nursing is a practice profession, clinical experiences are essential for applying what students have learned. However, clinical sites can be challenging to find, and with increasing numbers of nursing graduates, difficulties will continue to mount. In two web-based 2018 surveys of BONs the scarcity of clinical placements were discussed and some examples of alternative sites (e.g., prisons, mental/physical disorders counseling centers, day care centers, Head Start programs, ambulatory care settings, and hospices) were provided (NCSBN, unpublished findings). To alleviate the difficulty in finding clinical sites, Hawaii enacted a bill that created a tax credit for APRNs, physicians, and pharmacists who provide clinical education to healthcare students (S.B. 2298, Hawaii. 2018). 
Indiana sought to entice didactic and clinical faculty with loan repayment grants in a failed bill (S.B. 28, Ind. 2018). It remains to be seen if such incentives result in more willing clinical faculty.

The use of qualified preceptors in prelicensure nursing programs is an excellent way to provide quality clinical experiences. One issue BONs struggle with is determining minimum qualifications of preceptors in prelicensure nursing programs. In another webbased survey, $73 \%$ of the $32 \mathrm{BONs}$ responding confirmed they establish requirements for preceptors (NCSBN, unpublished findings). Similarly, L'Ecuyer, von der Lancken, Malloy, Meyer \& Hyde (2018) reviewed the BONs' rules and regulations related to preceptors and found some commonalities among the states include $\mathrm{RN}$ licensure, degree requirements, and years of experience. These authors provided an extensive table of state requirements related to preceptors in undergraduate programs, which would be useful to faculty.

Other examples of quality clinical experiences include dedicated education units (DEUs), which is a collaborative model where clinical service partners with nursing education. This is a mutually beneficial situation where staff nurses serve as clinical instructors, while faculty support and guide the clinical education. In the DEU model, faculty are less focused on direct patient care and, instead, promote the development of clinical reasoning and supporting the role of the staff nurse (Rusch et al., 2018). There have been questions; however, about how to best implement and sustain the model. Recently, Rusch et al. (2018) developed resources that clarify the use of the model for faculty, staff nurses, and students. One resource is a faculty rounding guide where faculty rounds with the student and discusses care and priorities. A progression guide to allow for shared expectations of the students' progress is another resource. These guides are particularly useful for faculty new to the model as they provide consistency and more precision in the implementation of DEUs.

\section{Clinical Reasoning}

In 2018, nursing education focused on clinical decision making and reasoning, and this is clearly the future in nursing education. New research in 2018 added clarity to the foundations of clinical decision making that are built upon a combination of scientific knowledge, intuition, and context (Krishnan, 2018). Similarly, new analysis of clinical reasoning foundations yielded six key concepts: (a) context of practice, (b) experience over time, (c) continuum of reflection, (d) multiple practice opportunities, (e) discourse, and (f) meaningful feedback (Jessee, 2018). These analyses will be useful to faculty as they begin to integrate more clinical reasoning and decision making into their teaching. For example, with Jessee's theory, faculty might design purposeful experiences in similar contexts to promote an understanding of subtle differences in similar situations. Krishnan (2018) stressed the importance of using the basis of the cognitive model for decision making (systematic-positivist) and for teaching decision making, along with the intuitive model (intuitive-humanistic). The systematic-positivist model is based on the information processing theory, which is one of the most influential theories on decision making in nursing and medicine. The model emphasizes explicit, analytical and cognitive processes in decision making. The intuitivehumanistic model is rooted in phenomenology and emphasizes the importance of intuition, wisdom, and experience in decision making.

An expert clinician must also interpret changing patient conditions as patient information is provided. Promising new research has reviewed the validity of the Lasater Clinical Judgment Rubric (LCJR) for interpreting changing patient conditions. The LCJR focuses on four phases: (a) noticing, (b) interpreting, (c) responding, and (d) reflecting. It is frequently used for assessing clinical judgment in simulation; however, usually with one or only a few observations. A 2018 study evaluating junior- and senior-level undergraduate nursing students allowed for multiple opportunities to assess student performance in the clinical setting and found senior students had a statistically significantly higher mean score than juniors. This is evidence that clinical judgment can be assessed in the students' clinical experiences (Manetti, 2018). The authors acknowledge more studies are needed to confirm validity of the tool in the clinical setting.

\section{Apprenticeships}

In the past, nursing apprenticeships had a slight negative connotation. Apprenticeships were on-the-job training common in hospital diploma programs in the early 1900s until the 1950s. In those early apprenticeships, students often worked long shifts and had little supervision. It was after the 1950s when nursing programs migrated to universities (baccalaureate programs) at a faster pace and when associate degree programs developed (Simmons University, 2014; Mahaffey, 2002).

There is a positive resurgence of apprenticeships today. In 2016 the U.S. Department of Labor announced over \$50.5 million in grants to 37 states to expand the use of apprenticeships (Kentucky Press News Service, 2016). Some of this money is being used for nurse extern and transition to practice programs, which are used in conjunction with nursing education programs and are not in themselves a nursing education program. Norton Healthcare in Kentucky developed the Student Nurse Apprenticeship Program (SNAP) that provides students clinical experiences as they matriculate through their nursing education program (Norton Healthcare, 2018). In Minnesota, Fairview Health Services developed an apprenticeship program for RN-to-BSN students as another way to increase the percentage of baccalaureate educated nurses in the workforce (Smith, 2018). Wyoming and Nevada developed apprenticeship programs with the input of their BONs. The Nevada BON developed skills' lists for RN and LPN/LVN apprentices, as well as program guidelines (i.e., the program must be approved by the BON and accredited by a national nursing accrediting agency) (Nevada BON, 2018). Illinois, Maryland, Texas, Washington, and South Dakota are involved in apprenticeship program pilots (U. S. Department of Labor [DOL], 2018a). 


\section{Graduate Nursing Education}

In 2004, the American Associate of Colleges of Nursing (AACN) called for APRNs to be educated with a DNP degree, rather than a master's degree, by 2015; however, this goal has not been met. Yet, there has been a national increase in DNP programs from fewer than 25 in 2006 to 336 in 2017, with another 121 planned. During that same time, PhD programs have stabilized between 100 and 150 programs(American Association of Colleges of Nursing [AACN], 2018a).

In May of 2018, the National Organization of Nurse Practitioner Faculties (NONPF) declared the educational exit point for nurse practitioners should be the DNP by 2025. NONPF has long supported the development of the DNP and, by 2025, will no longer support the exit for nurse practitioners at the master's level. The DNP, as developed, is not additional curricula added to the existing master's curricula, but rather is structured on written, population-focused competencies and educational objectives specific to the DNP. The National Association for Clinical Nurse Specialists (NACNS) and the American Association of Nurse Anesthetists (AANA) have previously issued positions on the DNP as entry to their specific roles (National Organization of Nurse Practitioner Faculties, 2018).

The AANA believes the entry level degree for CRNAs should be the DNP or doctorate of nurse anesthesia practice (DNAP). The Council for Accreditation for nurse anesthetists established the doctoral degree as the required terminal degree for CNRAs by 2025 (Council on Accreditation, n.d.) Additionally, NACNS issued a similar intention for CNSs by 2030 (National Association of Clinical Nurse Specialist, 2015). To date, there has not been a call for the doctorate requirement for nurse midwives by the Association of Nurse Midwives or their certification organization.

While DNP programs are booming (more than 4,855 doctoral degrees were awarded, 773 were PhDs in 2016), PhD programs are lagging (Broome, 2018). In 2018, Feeg \& Mancino (2018a) reported a slight downward trajectory on new graduates' plans to pursue a research-based degree and a simultaneous upward trajectory on pursuing a practice-based doctorate compared with 2017.

While nurses with clinical doctorate degrees are certainly important, the $\mathrm{PhD}$ prepares nurse scientists to create new knowledge, test the effectiveness of interventions, and translate research into policy. This leads the call for more PhD-educated researchers as clinicians rely on valid research for their work with patients, families, and communities (Broome, 2018). An assessment of quantitative research methods in top National Institutes of Health-ranked schools of nursing was conducted to support this call for well-prepared nurse scientists and to strengthen the rigor and consistency of quantitative research skills in PhD nursing programs. The results led to the development of core competencies for quantitative methods to be used in nursing $\mathrm{PhD}$ programs. Universities with nursing $\mathrm{PhD}$ programs will find these competencies valuable as they evaluate their programs (Thompson et al., 2018).

The rigor and role of DNP programs are other issues in graduate nursing education. The general difference between $\mathrm{PhD}$ and DNP education is that DNP students do not conduct research as part of their DNP project (Brockopp, 2018). Brockopp asserts that the research process is often the logical way for resolving clinical questions and the quality improvement projects that DNP students are encouraged to conduct are not as publishable as research and are largely not funded. Students identified further challenges in DNP programs. The students often reported non-DNP faculty were not prepared to teach them and projects lacked consistency and were irrelevant at times. The proposed solution is a set of guidelines for DNP projects to ensure rigor and consistency across the nation (Volkert and Johnston, 2018).

\section{Faculty Shortage}

While new graduate employment has improved since the 2008 recession, the faculty shortage in the United States remains a problem. AACN's 2018 report $(n=871)$ on baccalaureate and higher education faculty vacancies (Li, Turinetti, \& Fang, 2018) found 1,715 fulltime vacancies for the 21,685 full-time budgeted positions ( $7.9 \%)$. That translates to $488(56 \%)$ schools with vacant full-time positions. Another 138 schools (15.8\%) reported no vacancies but needing additional faculty. Similarly, in their latest published statistics on faculty vacancies (NLN, 2017), the NLN ( $\mathrm{n}=839$ ), whose sample includes nursing programs at all education levels, reported many nursing faculty vacancies, including: (a) 31\% (full time equivalent) for BSN programs, (b) $30 \%$ for ADN programs, (c) $17 \%$ for Master of Science in Nursing programs, (d) 12\% for doctoral programs, (e) $6 \%$ for LPN programs, (f) $3 \%$ for RN to BSN programs, and (g) $1 \%$ for diploma programs. In the 2008-2009 AACN faculty vacancy survey $(\mathrm{n}=449)$, Fang \& Htut (2009) found faculty vacancies to be similar to those seen today- $7.6 \%$ total vacancies, $62.8 \%$ of schools reporting vacancies, and $17.8 \%$ of schools with no vacancies but needing additional faculty.

Despite recent increases in DNP educated nurses (AACN, 2018a) taking faculty positions, the faculty shortage persists. Literature provides some guidance and suggestions about how to address the shortage. Fritz (2018) conducted an integrative review identifying barriers and facilitators when nurses transition from clinical positions to educator roles. Barriers included role clarity, lack of orientation and mentoring, and inadequate preparation for educator skills. The studies reviewed identified some successful facilitators, such as developing formal mentoring programs and creating courses for developing mentoring skills. AACN recently released a preferred vision of the professoriate in baccalaureate and graduate nursing programs related to role clarity (AACN, 2018b), which outlines the vision of qualified faculty in meeting the demands of the future. This would help clarify the educator role for novice educators in baccalaureate and graduate nursing programs. A similar document would be beneficial for faculty in practical, associate, and diploma nursing pro-

S14 Journal of Nursing Regulation 
grams. Lastly, Elpern and Disch (2018) suggest using retired nurses to complement the workforce given the looming nursing shortage. Retired faculty could serve as standardized patients in simulation centers or could assist students with procedures in learning laboratories. Additionally, they could provide lectures in their areas of expertise, conduct faculty development workshops, and tutor students. This creative option could lessen the load on educators who are overworked because of the chronic faculty shortage.

\section{Regulatory Implications}

- For many years, education has measured the outcomes of students. Today, there is a solid movement to identify evidence-based metrics to measure outcomes of nursing education. This has clear implications for regulators. Research may provide specific indicators and warning signs to identify programs at risk so administrators and BONs can address them prior to any adverse student outcomes.

- There is a focus on designing quality clinical experiences in alternative clinical settings. The U.S. DOL's emphasis on apprenticeships may be one way to foster richer clinical experiences and more partnerships between education and practice.

- Globally there is a shortage of nurses that is predicted to continue to 2030 (World Health Organization [WHO], 2016). It is likely, therefore, that more U.S. faculty will be teaching by distance education to students around the world, posing licensure issues and questions.

\section{Healthcare Delivery}

At the 1978 International Conference on Primary Health Care, world leaders and health experts convened by the World Health Organization (WHO) and the United Nations International Children's Fund endorsed the Alma-Ata Declaration: "to protect and promote the health of all the people of the world." The declaration identified primary care as the cornerstone of healthy, thriving communities; the foundation for integrating the full spectrum of health and social services to improve health outcomes; and the key to sustainable, accessible, and equitable health systems (Chokshi E Cohen, 2018).

Despite progress, the goal of quality care for all, envisioned in the Alma-Ata Declaration, remains elusive. Today, as in 1978, healthcare leaders continue to ponder solutions to the same struggles-access to basic healthcare for underserved and disadvantaged populations. In the United States, the emergency department is often the entryway into the healthcare system. This drives up the escalating costs of healthcare and leads many to question whether the system is sustainable for the long term (Chokshi \& Cohen, 2018).

In 1978 , on a per capita basis, healthcare spending in constant dollars was $\$ 2,627$ and, in 2016 , that more than tripled to $\$ 10,348$. Despite this extraordinary spending on healthcare, primary care receives an estimated 7 cents for every dollar spent; however, there is not a defined or uniform way of determining spending on primary care (Chokshi \& Cohen, 2018).

To add to the enigma of providing primary care to the underserved is the pending physician shortage. In 2018, the Association of American Medical Colleges undertook a major study of physician supply and demand projecting an overall primary care physician (PCP) shortage between 14,800 and 49,300 by 2030 . The range of the shortfall reflects different assumptions about the growth in the supply of APRNs and physician assistants and their role in primary care delivery. The study noted the aging U.S. population will cause increased PCP demand, while the aging physician population (physicians aged 65 years and older account for $13.5 \%$ of the active workforce) will lead to only modest increases in the PCP supply at best. The study also noted the projections did not account for equitable access to care and if such concerns were included, the projected shortages would likely be higher (Association of American Medical Colleges, 2018). While the United States continues to face a crisis in access to care and a pending shortage of physicians, there are new studies providing unequivocal evidence that APRNs could assist in solving these primary care issues.

In 2018, more evidence emerged demonstrating the comparability of outcomes and the lower cost of services associated with care by of APRNs (Traczynski, and Udalova, 2018; Buerhaus, 2018). States without restrictions on practice found significantly greater numbers of residents who report a usual source of care and greater satisfaction with care (Sonenberg and Knepper, 2017), and they are more often listed among the states with highest rankings in measures of state health outcomes. Conversely, states that perform poorly on state health outcomes measures such as access to health, preventive care, and immunizations (areas for which APRNs might particularly add value) are states with the most restrictive scopes for these underutilized roles (Radley, 2018).

The Institute of Medicine, the National Governors Association (NGA), and the Federal Trade Commission (FTC) have called for the removal of barriers to full APRN practice, with the most recent policy statement coming from the Brookings Institution, which is an economic research group. Through their Hamilton Project initiative, the Brookings Institute generates evidence-based policy proposals to promote economic growth. Recently, they advocated for removing barriers to the practice and prescribing of non-physician providers, such as APRNs as a remedy to U.S. access to care issues, elaborated on the consistently safe and effective outcomes by nonphysician providers, and emphasized the potential cost savings to states (Adams and Markowitz, 2018). The cost savings point is key and is another way in which physician involvement presents a barrier to care; namely, subjecting APRNs to physician supervision through required collaborative agreements that frequently increases their costs to provide care (Martsolf and Kandrack, 2017) Some physicians charge an additional 20\% to APRNs who are required to have a collaborative agreement (Martin, in press). Also in 2018, the American 
Enterprise Institute's publication on nurse practitioners as a solution to the primary care crisis concluded definitively that, "state level scope of practice restrictions do not help protect the public from subpar healthcare" (Buerhaus, 2018).

Today, the United States faces care and access challenges in rural areas and APRNs are moving quickly to fill these gaps. Nurse practitioners increased their presence in rural care by $43 \%$ from 2008 to 2016 (Heath, 2018). Eliminating restrictions on nurse practitioners and nurse midwives would result in substantial benefits to states such as: (a) women are more likely to be attended during labor in a county that allows full practice for certified nurse midwives, (b) patients seeing a nurse practitioner in rural areas are more likely to have a usual source of healthcare, get an appointment when desired, and have routine checkups, and (c) chronic disease management for these patients is comparable as is cancer screening and other ambulatory care measures (Buerhaus, 2018).

In addition to filling a much-needed role in the primary and rural care shortages, APRNs are positioned to become an important part of the solution to the nation's opioid crisis. The passage of the Comprehensive Addiction and Recovery Act in 2016 enabled nurse practitioners to become prescribers of medication-assisted treatment for opioid addiction. Nurse practitioners rose to that care challenge and, today, nearly 7,000 have attained the prescribing waiver (American Association of Nurse Practitioners, 2018). An amendment to the original legislation (U.S. Bill HR6, enacted October 2018) has enabled other APRN roles to also seek additional addiction treatment training and become prescribers of much needed addiction treatment.

To address the physician shortage, the American Hospital Association supports the Resident Physician Shortage Act of 2017, which seeks to increase the number of residency slots for primary care and specialty physicians in the United States by 15,000 over a 5 year period with at least $50 \%$ of the additional slots directed to a shortage specialty residency program (American Hospital Association [AHA], 2018b). Hackey, et. al. (2018) suggest such efforts are still insufficient to meet the supply needs because geographical distribution issues still exist since physicians are not choosing to practice in some areas with great shortages. The authors recommend physician assistants and nurse practitioners take more leadership roles to fill these needs. The findings of Xue, et al. (2018) lend credence to this assessment, noting that states with full practice authority for nurse practitioners had the highest nurse practitioners supply in rural and primary care health professional shortage area counties. The authors reported the nurse practitioner workforce will be the fastest growing primary care workforce from 2013-2025 and the only primary care profession projected to have a surplus in each state.

\section{Telehealth}

Forty years ago, telehealth research was already underway. Leaders in the field included the Public Health Department, NASA, the Department of Defense and the U.S. Health and Human Services Department. An early success story was a partnership between NASA and the Indian Health Services. These government agencies worked together on a project called Space Technology Applied to Rural Papago Advanced Health Care (STARPAHC). Telehealth services were provided to Native Americans on the Papago Reservation in A rizona and astronauts in space. Developers used microwave technology and transmitted X-ray photographs, electrocardiographs, and other medical information to and from the Public Health Service hospital. (eVisit, 2018)

The continued ascent of telehealth remains at the forefront of strategies to expand healthcare access, particularly among vulnerable populations and in non-traditional settings (Holland, 2018). Data from the 2017 NCSBN National Workforce Survey indicated $45.7 \%$ of RNs and $44.1 \%$ of LPNs provide telehealth services across a state border (Smiley et. al., 2018). These numbers may rapidly increase over the next few years with the expansion of virtual care and remote monitoring among many other progressive changes that require nurses to practice remotely in more than one state.

It is estimated that telemedicine will be a $\$ 9.5$ billion industry by 2022 (MarketWatch, August 2018). The adoption and expansion of telehealth technologies is buoyed by several recent, high-profile investments. First, the Federal Communications Commission proposed creating a $\$ 100$ million Connected Care Pilot Program to support telehealth among low-income Americans, especially those living in rural areas and veterans (AHA, 2018a). This new initiative is specifically created to address the overlap between lack of broadband deployment in low income communities and poor health outcomes (Manchester, 2018). The Centers for Medicare \& Medicaid Services (CMS) proposed adding new codes for remote monitoring, which indicates some interest in reimbursement for monitoring patients from a distance (Centers for Medicare \& Medicaid Services [CMS], 2018).

Additionally, CVS Health offers "video visits" through its MinuteClinic treatment facilities in California and other states, which Los Angeles Times writer David Lazarus cited as "a smart use of technology to make healthcare more accessible, especially for relatively minor medical issues - which can turn into major concerns if not addressed early" (Lazarus, 2018). Several other states, such as Texas and North Carolina, have opted to participate in Health-E-Access, a program that sends mobile telemedicine units to schools (Holland, 2018).

A recent study on the effectiveness of nurse-led telemedicine teams in a regional healthcare system showed a significant decrease across several acute stroke metrics (Fowler et al., in press). Additional evidence shows rural health systems can reduce patient mortality while reducing costs (Siwicki, 2018), help patients and clinicians more effectively manage chronic diseases, such as diabetes and chronic heart failure (Kim, Park, Lee, Jung, \& Park, 2018; Jiménez-Marrero et al., 2018), and use mental health technologies that have considerable promise (Wozney et al., 2018). 


\section{Remote Patient Monitoring}

For several years, the shift from facility-based care to home and community care has been predicated on the advent of remote patient monitoring. Remote patient monitoring includes devices that allow a healthcare team to monitor a patient's vital signs and changes in condition from a distance and is expected to become a standard fixture of care. Although the remote patient-monitoring systems market is expected to be $\$ 46$ billion in 2020 (Arndt, 2018), the actual benefit of these systems may not match the use. A recent review (Noah, et al, 2018). evaluating randomized controlled trials on the impact of remote patient monitoring on clinical outcomes of various monitoring devices (e.g., blood pressure monitors, ambulatory electrocardiograms, cardiac event recorders, positive airway pressure machines, electronic weight scales, physical activity trackers and accelerometers, spirometers, and pulse oximeters) found the following:

- Improved outcomes for patients with select conditions, including obstructive pulmonary disease, Parkinson's disease, hypertension, and low back pain

- Increased physical activity and weight loss using various activity trackers showed mixed results

- Interventions based on validated health behavior models, care pathways, and tailored coaching were the most successful.

The safety issues associated with care delivered by remote patient monitoring identified by Schlachta-Fairchild, Elfrink and Deickman in 2008 remain safety issues today, and include: (a) complex equipment, (b) possible malfunctioning equipment, (c) potential adverse effects on patient management decisions through delayed or missing information, (d) misunderstood advice, and (e) inaccurate findings due to patient or caregiver error.

\section{Emerging Technology}

In a 1979 introductory course on the use of computers in nursing, students characterized computers as 'debumanizing', 'unreliable', 'complicated', and 'taking people's jobs away'. (Ronald, 1979).

Emerging technologies continue to play a critical role in advancing healthcare practice and research. The advent of big data and use of sophisticated analytics revolutionized the study of public health, which helped to identify the social, environmental, and medical determinants of community well-being (Gamache, Kharrazi, \& Weiner, 2018). Additionally, the application of cloud computing and artificial intelligence (AI) to facilitate efficient exchange of health information electronically is now closer to reality (Farr, 2018a). Personalized healthcare leveraging clinical genetics and genomics services, as well as innovative medical procedures are also changing the way in which vital services are delivered and patients' health monitored (Flannery, 2018; Mathioudakis et al., 2018). Shared Ledger Technology, such as blockchain, has huge potential for the future of computing with the promise of supplying regulators with a streamlined global credential verification system in the future. All these advancements are occurring against a backdrop of broader technology-driven societal change.

\section{Artificial Intelligence-Assisted Diagnosis}

As outcomes of remote patient monitoring may be currently overstated, the much-touted potential of AI-assisted diagnosis is currently falling short of its envisioned usefulness. Take for instance recent coverage of IBM Watson's poor diagnostic track record in oncological settings that has raised concerns over incorrect and possibly unsafe treatment recommendations being offered (Hernandez \& Greenwald, 2018). Despite such high-profile setbacks, this same technology, or similar versions, is utilized worldwide with an ever-expanding customer base (Miliard, 2018). The rapid ascent of technology has fundamentally altered the day-to-day management of patient care and revolutionized how researchers harness increased computing power to glean clinical insight. At a minimum, the complementary role technology will play in healthcare practice and research is undeniable. Thus, "it is imperative that regulation keeps up with all technological developments, and that it is appropriately enforced, so that patients are kept safe, however they choose to access care" (Browne, 2018).

\section{Personalized Technology}

The healthcare industry's traditional models of innovation (basic and applied research followed by development and commercialization) are often at odds with the rapid pace of new technology deployment (Bhatti, del Castillo, Olson, \& Darzi, 2018). In response, new human-centered approaches to healthcare innovation via collaborative co-creation ventures are beginning to take root. Three such models include the Helix Centre at Imperial College London, the Center for Innovation at the Mayo Clinic, and the Consortium for Medical Technologies at Massachusetts General Hospital. Each locates interdisciplinary innovation laboratories within or near hospital environments; involves diverse stakeholders beyond clinicians (e.g., designers, engineers, business professionals, and patients) early in the innovation process; and engages end users (e.g., patients) in customizing solutions for their own needs (Bhatti, del Castillo, Olson, \& Darzi, 2018). Similarly, Humana recently launched a new Digital Health and Analytics Center in Boston, Massachusetts (Leventhal, 2018). These interdisciplinary research collaboratives seek to leverage public and private expertise using advanced data science and clinical experience to enable personalized medical advancements in the form of proactive, preventive measures (Fröhlich et al., 2018). The earliest innovations resulting from these collaborations should begin to appear over the course of the next few years. 
These synergistic efforts hold great promise for transforming how individuals monitor their health and how clinicians manage chronic illness and detect disease progression. Leading this new wave is the mobile medical applications (apps) market, which is forecasted to grow to $\$ 11.2$ billion by 2025 . Natural Cycles, a mobile fertility app, recently became the first ever digital contraceptive device to win U.S. Federal Drug Administration (FDA) marketing approval (Chan, 2018). Similarly, SimpleC's "Companion" software encourages medication adherence, (Greene, 2018), mobile service Fit4D aims to connect certified diabetes educators directly to patients (Harrison, 2018), and Google partnered with the American Medical Association (AMA) to encourage mobile health information technology development to support wearable devices and apps (American Medical Association [AMA], 2018b). Mobile health technologies have also been offered to support sustainable and healthy lifestyles among aging populations (Faiola, \& Isola, 2018) and to effectively manage chronic diseases (Kim et al., 2018).

In more traditional medical settings (e.g., hospitals, outpatient community health centers), new experimental technology is leading to breakthroughs in disease detection and patient care management. Researchers say the "Na-Nose," which uses nanorays to analyze breath, can identify Parkinson's disease, various cancers, kidney failure, multiple sclerosis, and Crohn's disease with 86\% accuracy (Scutti, 2017). Robotic-assisted surgical procedures have also been hailed for their precision and improved clinical outcomes (Ashrafian, Clancy, Grover, \& Darzi, 2017). Further, Leaf Healthcare announced the success of their enhanced wireless patient sensor system that enables nurses at the point of care to confirm the patient turn they just completed adequately protects against pressure injuries (Densford, 2018; Pickham et al., 2018). Finally, the market for surgical chips, which are small medical devices implanted in the operating room to enable patient identification and tracking, medical records management, and healthcare quality control is set to surge by 2027 (MarketWatch, September 2018).

\section{Shared Ledger Technology (Blockchain)}

Blockchain is a distributed shared ledger technology, meaning there is not a central database tracking data, but rather it is a distributed database managed and maintained by a specific blockchain network (which could be either public, semiprivate, or private based upon the implementation). In other words, instead of all data being stored and accessed from a single location, duplicate datasets are hosted on many computers, all of which are constantly reconciling with each other by adding another 'block' of data at regular intervals to the shared chain of data blocks. Because there is no master database, blockchain is very difficult to corrupt (BlockGeeks, 2018).

Blockchain technology has the potential to fundamentally resolve the issue of multiple entities not trusting each other to control data and to keep it safe within one continually available database. It allows transparency and storage of transactions, which makes it available for inspection by all parties. Trust is replaced by strong cryptographic mathematical proofs that provide a high level of security. Initially developed to manage digital currency such as Bitcoin, technology experts are beginning to acknowledge a huge potential for its use in other fields. Abra is another example of blockchain implementation that allows the digital transfer of funds between two individuals while circumventing any established banking system, making the process more efficient and less costly.

Because of the tamper-proof, shared nature of blockchain and its suitability for use with 'ledger' type datasets, experts also see a variety of potential uses for it in healthcare. Blockchain may lend itself to addressing interoperability challenges currently plaguing disparate electronic health record solutions (Linn \& Koo, 2016). A blockchain ledger could be used to obtain patient consent to share medical records with multiple providers and, thus, provide a boon to interdisciplinary and telehealth care. Potentially, this could lessen the hurdles involved in sharing medical data across state lines where privacy and consent laws differ. Additionally, blockchain could facilitate incentives for patients_tracking and rewarding them for following their care plan, for example (Bean, 2018).

In education, blockchain is viewed as a reliable way to track and vet undergraduate and continuing education conducted via distance learning, as well as to catalog and review a student's clinical encounters, including preceptor evaluations. Post-licensure, blockchain could be applied to tracking continuing education, case logs or medical records, and discipline processes (Peters, 2017).

These same features — enduring, inalterable, and decentralized — are attractive traits as regulators imagine the next generation of licensure verification, potentially even across international borders. In its ultimate form, education, licensure, and continuing education information might all exist within a single, tamper-proof repository, eliminating the need to re-verify each item (Peters, 2017) such as when a nurse or other provider relocates or practices in another jurisdiction or country.

Organizations will need to evaluate the application of blockchain to determine if it is the right solution to their problem. If multiple parties do not trust each other to manage the transactional data in one database, and have a need for transactions to be transparent, then blockchain could be a viable solution. On the other hand, if the parties trust a single source or a central database to manage and distribute the collected data in a secure manner, then blockchain is perhaps not the best solution.

The full potential of blockchain to transform healthcare and regulation, remains to be realized as challenges continue to be resolved. In many applications, the privacy of transactional data is central, specifically in healthcare, where there is a need to protect specific patient-related data. Healthcare organizations and regulators will also grapple with how blockchain technology interacts with existing privacy, information security, and data-sharing laws. 
Blockchain cryptographic computations are massive, requiring a lot of computing power, and a large investment in hardware, including the resources needed to maintain them. However, it is possible to reduce the cost and computational power in a private blockchain of known entities, such as licensure data, where entities have built a semi-trusting environment to build a network of licensee credential blocks.

Ultimately, the full realization of blockchain will involve an evolution of both technological hardware and regulations related to information security, as well as cultural shifts relating to trust in the technology and terminology. Only then will regulators see the streamlined global credential verification system that the future might hold for them.

\section{Regulatory Implications}

- Given the rapid expansion of nursing services driven by telehealth technologies, there is a need for the Nurse Licensure Compact (NLC) more than ever. Nonmember states put a financial strain on nurses and employers as the number of licenses nurses require to treat patients across state borders rises.

- The increase in telehealth triage, diagnosis, and treatment has implications for nursing regulators. Who is providing the care? While many are APRNs, what is the role of the RN and LPN/LVN in triage and telephonic services? As the need increases, regulators should consider providing official guidance to nurses engaged in telehealth at all levels.

- Regulators should expect the expansion of telehealth nursing services to extend across international borders. Currently, there is little collaboration among international regulators to address licensing telehealth providers, which is needed to ensure nurses who provide telehealth to patients in the United States have U.S. licenses and meet U.S. standards of care.

- As personalized technology continues to push healthcare into new and uncharted territories, it is imperative regulators remain vigilant and ever-mindful of the ways in which novel applications of advanced analytics and medical technology can impact patient safety. When the technology fails and results in patient harm, who is responsible? This will be a challenge facing regulators in the coming years.

- Regulators will need to understand the new technology and its implementation process. They will need to understand the role of the nurse and other team members to determine accountability.

- As the complexity of healthcare delivery increases so might the number of individuals on the healthcare team. When multiple individuals are accountable for a patient's care in a highly technical environment, which board(s) will address the issue? Scientists as well as policymakers are already contemplating the issues. Regulatory oversight to ensure patient safety remains at the forefront regardless of how consumers access healthcare services (Browne, 2018).

\section{Legislation and Policy Issues The Nurse Licensure Compact}

The enhanced NLC (eNLC) officially became effective on July 20, 2017, when North Carolina was the 26th state to enact the model eNLC legislation. After a 6-month transition period, eNLC implementation occurred on January 19, 2018 with a total of 29 states initially participating (Kappel, 2018). Once the enhanced version of the NLC was fully implemented, it replaced, and negated, the original compact in place since 2000 (NCSBN, 2018c).

During the 2018 legislative season, Kansas and Louisiana enacted eNLC legislation and will implement the eNLC on July 1, 2019 (NCSBN, 2018a). Looking ahead, approximately 10 states are planning to introduce eNLC legislation in the 2019 session and additional states are preparing to introduce in 2020.

Currently, 31 states are members of the eNLC (NCSBN, 2018a). For a full list of participating states, please see nursecompact.com. New states are consistently entering the eNLC, so nurses and their employers should check the Nursys system regularly to determine if their privilege to practice in a state has changed.

The NLC is no longer alone in increasing healthcare mobility. Other health professions have added licensure mobility compacts of their own, and acceptance of such compacts by state policymakers is growing. Though the language and mechanisms in each compact differ slightly, the goal of removing barriers to practice across state lines is the common thread in each.

The Interstate Medical Licensure Compact is the most widely recognized of these and has been enacted in 24 states and one territory (Interstate Medical Licensure Compact, 2018). The compact for emergency medical service personnel, known as REPLICA (Recognition of EMS Personnel Licensure Interstate CompAct) has grown to 16 states (National Registry of Emergency Medical Technicians, n.d.). The Physical Therapy Compact has been enacted in 21 states; however, only five of these are issuing compact privileges (PT Compact, n.d.). The Psychology Interjurisdictional Compact, PSYPACT, will be enacted when seven states become members; currently membership stands at six (Association of State and Provincial Psychology Boards, n.d.).

In January 2017, the U.S. DOL announced an award of $\$ 7.5$ million to the National Conference of State Legislatures (NCSL), NGA, and the Council of State Governments (CSG). The purpose of the grant is to study ways to improve geographic mobility for occupations requiring a license and to determine the licensing criteria to ensure licensing requirements are not overly burdensome (DOL, 
2017). The DOL issued an additional $\$ 7$ million to states and state-based organizations, including NCSL and CSG. The DOL is also focusing on occupational licensing portability for military spouses through the creation of a new webpage that posts licensing requirements for all states (U.S. DOL, 2018b).

The FTC has also taken an interest in license portability. After swearing-in five new commissioners in 2018, the FTC released a report, Policy Perspectives: Options to Enbance Occupational License Portability, in September 2018 that addressed ways to improve occupational license portability across state lines and investigated interstate compacts such as the NLC. The report focuses on the benefits of occupational license portability and the next steps that can be taken to increase portability. The study supports mutual recognition of licenses and reducing barriers for military spouses (Federal Trade Commission, 2018).

\section{The Consensus Model for APRN Licensure, Accreditation, Certification and Education: An Update}

Since the dissemination of the APRN Consensus Model in 2008, NCSBN, along with BONs and many other professional organizations and stakeholders, have worked to have the model adopted by all U.S. jurisdictions. Significant progress has been made. Currently, the model's elements stand at near $80 \%$ completion (NCSBN, 2018b). In 36 states and territories, APRNs are practicing and prescribing autonomously (NCSBN, 2018b).

The 2018 legislative session saw several successes for the Consensus Model (NCSBN, 2008). Florida enacted legislation to align the title of APRN from the previous Advanced Registered Nurse Practitioner (H.B. 1337, Fla. 2018). With Michigan and Oklahoma aligning the title in the 2017 legislative session, the total number of states to advance the title element is 41 (NCSBN, 2018b). Florida's House Bill 1337 clarified licensure as the form of regulation over the practitioners, replacing issuing a certificate (H.B. 1337, Fla. 2018). Both Florida and Michigan recognized CNSs as APRNs over the last two legislative sessions. The advancements in these states bring the total number of states recognizing the CNS to 48, with only Mississippi and New Hampshire remaining unaligned (Bousfield, 2008). In January 2018, Guam's legislature passed a bill advancing independent practice and prescribing for all APRN roles (Camacho Torres, 2018). Senator Mary Camacho Torres, a sponsor of Guam's legislation said:

I don't think there is an 'easy fix' for all of our problems. However, expanding the practice authority of our highly trained nurses will belp alleviate some of the burden. It will also provide an incentive to attract APRNs from off island and to our youth to pursue this career (Camacho Torres, 2018).

\section{Removing Barriers for Veterans}

On May 11, 2018, the U.S. Department of Veteran Affairs released its final rule addressing the authority of veteran affairs (VA) healthcare providers to deliver telehealth services across state lines (U.S. Department of Veteran Affairs, 2018). NCSBN consulted throughout the process and submitted official comments following the release of the proposed rule in October of 2017.

The VA Maintaining Systems and Strengthening Integrated Outside Networks (MISSION) Act of 2018 was passed by the House (H.R. 5674) and the Senate (S.2372) and President Trump signed the bill on June 6, 2018. The law includes several provisions of interest to BONs. It gives VA the authority to deny, suspend, or revoke the eligibility of a non-VA healthcare provider, such as VA private contractor, to participate in the community care program if the provider has was previously removed from VA employment or had their license revoked. The Government Accountability Office is required to issue a report on the implementation of this provision two years after enactment (VA MISSION Act, 2018).

Another provision allows any licensed healthcare provider to be considered an authorized recipient and user from the national network of state-based prescription drug monitoring programs (PDMPs) for querying and receiving data. No state can restrict the access of licensed healthcare providers or delegates working in the VA from accessing that state's PDMPs. (VA Mission Act, 2018).

The VA MISSION Act also includes the legislative language of the Veterans e-Health and Telemedicine Support (VETS) Act, which gives the VA statutory authority to allow healthcare professionals employed by the VA to practice telemedicine regardless of the location of the provider or patient during treatment. This rule only applies to those employed directly by the VA and does not extend to contractors. The scope of practice is defined using federal law and regulation or the laws and regulations of the provider's state of licensure. Prescribing abilities are determined through the provider's state of licensure (VA MISSION Act, 2018). The final rule went into effect on June 11, 2018 just six days after the VA MISSION Act became law.

\section{From Soldier to Nurse}

Another barrier regulators seek to remove is the lack of employment opportunities for military personnel with medical training. In the past, once these individuals left the service, there was no avenue for them to receive licensure recognition for the skills they gained. Figuring out the optimal method of comparing military veteran experience with civilian occupational positions has been an ongoing issue for decades.

In 2013, NCSBN reviewed and compared the curricula for several military roles to a standard practical nursing curriculum and found the Army 68WM6 comparable. In 2016, NCSBN conducted a similar analysis on the Air Force 4N031 (3 Skill Level) and Air Force BMTCP 4N051 (5 Skill Level) curricula and determined the Air Force 5 Skill Level to be comparable to the standard practical nurse curriculum. 
States have recently addressed comparable standards of veterans with medical experience as well. The Georgia BON released a statement addressing veterans with military training as graduates of nontraditional nursing education programs (Georgia BON, 2018). Arizona and Florida addressed the military transition via statute. In 2013, Arizona enacted H.B 20176 that allowed military veterans with appropriate medical experience to complete an LPN/LVN bridge course based on NCSBN's 2013 gap analysis (Arizona BON, 2018). The bill allows qualified veterans, based on previous experience, to take an accelerated LPN/LVN education route and to sit for the NCLEX-PN. (Arizona BON, 2018). Florida enacted H.B 29, also known as the Don Hahnfeldt Veteran and Military Family Opportunity Act. This bill allows licensing boards to "recognize certain military-issued credentials earned by active duty military members and their spouses for purposes of issuing a license in a healthcare profession" (Florida BON, 2018).

\section{Occupational Licensure: Barrier or Public Safety Defender}

Occupational licensure continues to top lawmakers' agendas. Compared to 1950 when only $5 \%$ of professions required licensure, nearly $25 \%$ of U.S. professions now require licensure to work (Nunn, 2018). In 1952, the CSG issued a report stating "there are at least seventy-five different professions, skills, trades or other occupations for which varying combinations of qualifications, examinations, and license are required to practice" (Spector and Frederick 1952). In 2016, nearly 1,100 occupations required a license in at least one state (National Conference of State Legislatures, 2017). A concerted effort to reverse the trend has taken hold at state capitals, as lawmakers question the necessity of licensure for various professions. In 2018, the requirements for obtaining and maintaining a license became part of the occupational licensure debate. Questions about licensure requirements include are they overly burdensome to licensees and do they lack a connection to public protection.

In 2015, the BLS found only eight instances where states, through legislation, de-licensed professions (Thornton et. al., 2015). One of those professions was Colorado morticians who were required to be licensed prior to 1981. (Thornton et. al., 2015). The law did not eliminate reference to morticians as title protection remained and licensure requirements (e.g., training hours) were included under titling provisions. (Thornton et. al., 2015). It is unclear what will occur if legislatures are successful in passing legislation to de-license other professions today, and what the future of those professions may look like if that occurs.

\section{State Occupational Licensure Measures}

In 2018, several bills proposed the de-licensing of professions. The trend is causing alarm among regulators and those advocating for public health and safety. Representative Paul Mosley of Arizona filed a dozen bills during the 2018 legislative session aimed at delicensing professions or exempting individuals from licensure for certain services (Leingang, 2018). Athletic trainers, barbers, and massage therapists were among the targets for de-licensing (Bill track, 2018). Representative Mosley also targeted health professions: H.B. 2406 would repeal licensure for behavioral health professions, and H.B. 2407 would de-license opticians (Leingang, 2018). Though unsuccessful, these efforts have created uncertainty among professional groups and regulators who should expect these legislative efforts to continue. John Glenn, a licensed architect in Arizona summed up his feelings of uncertainty, "when we're just haphazardly throwing stuff out there and seeing what sticks ... how do I know architects aren't next?" (Leingang, 2018). Like Arizona, legislatures across the country have targeted certain professions with de-licensing bills. Other states focused on mandating review of all licensed professions. For example, in 2017, Wisconsin Governor Scott Walker signed an executive order lessening regulatory burdens for several professionals including barbers, cosmetologists, and manicurists, and reducing licensure costs (Badger Institute, 2017). In addition to targeting certain professions for reform, the Governor supported a legislative effort calling for the Department of Public Safety and Professions to conduct a report reviewing all regulated professions in the state (Thomsen, 2018). As part of preparation of the report, the Department surveyed regulated professionals. (Thomsen, 2018). The results will inform the Department's recommendations to the legislature, and may result in legislation aimed at reducing regulation or de-licensing certain professions altogether. Although the review includes all 250 regulated professions in Wisconsin, the department caveats "This does not mean that the DSPS will be recommending the legislature deregulate all professions currently under the jurisdiction of our department" (Thomsen, 2018). Several additional states created review processes for boards, and 11 states are participating in a national effort led by the NCSL, Governor's Association, and the CSG to review occupational licensing laws and specific licensing requirements across multiple professions (Williams, 2018).

\section{North Carolina State Board of Dental Examiners v. Federal Trade Commission}

Legislative efforts continued in states attempting to address occupational licensure board and commission liability through the Supreme Court's decision in North Carolina State Board of Dental Examiners v. Federal Trade Commission ("NC Dental"). Policy organizations continue to push model legislation claiming a connection to the case while also advocating for reduced regulation.

Enacted bills requiring supervision over board decisions are plenty. In Louisiana, House Bill 748 requires the governor's office to review all regulatory and licensing agencies' actions and activities every five years and make the information available to the public (H.B. 748 , La. 2018). The bill does not address those requirements of active supervision the Supreme Court presented, namely the requirement that the review be before the action is final and the ability of the supervisor to modify or veto an action (North Carolina State Board of 
Dental Examiners v. Federal Trade Commission, 2015). Having enacted legislation in 2017 requiring licensure boards to submit proposed actions for review to an Occupational Licensing Review Commission, Mississippi Senate Bill 2526 further requires boards to review all rules at least every three years to determine whether they should be repealed or amended (S.B. 2526, Miss. 2018).

Nebraska's legislature enacted Legislative Bill 299, the Occupational Board Reform Act, a bill substantially similar to the American Legislative Exchange Council's ("ALEC") model act. The bill creates the Office of Supervision of Occupational Boards and charges the office with active supervision of occupational boards (L.B. 299, Neb. 2018). The bill aims to "protect the fundamental right of an individual to pursue an occupation" by requiring the use of the least restrictive regulations to protect consumers (L.B. 299, Neb. 2018). The bill also aims to ensure boards and board members avoid liability under federal antitrust laws. Outside of the model ALEC language, the bill allows an individual with a criminal history record to petition an occupational board to decide as to whether their criminal record would disqualify them from receiving the license or certification (L.B. 299, Neb. 2018).

While not directly related to the NC Dental decision, the increased scrutiny of occupational licensure laws has borne out in another way in some states, as the criteria for licensure of a person with a criminal history is re-examined. In Wyoming, a newly enacted law makes changes to the way a licensing board may consider an individual's convictions if they are unrelated to the occupation (S.B. 42, Wyo. 2018). In Indiana, licensing boards are now required to explicitly list the convictions that would disqualify an individual from receiving a license (H.B. 1245, Ind. 2018).

Several additional bills were introduced that focus on board-member immunity, active supervision of boards, and regulatory review processes. We can expect the introductions and enactments of bills related to regulation and NC Dental to continue into the 2019 legislative session.

\section{Federal Action Related to Licensure Reform}

In the past year, an increased interest in licensure reform at the federal level from libertarian and conservative think tanks such as the $\mathrm{R}$ Street Institute, Cato Institute, Heritage Fund, Charles Koch Foundation, and the Institute for Justice has formed. While these organizations dominate the conversation, there is some interest from left-leaning organizations on state licensing reform focusing on criminal justice reform, as mentioned previously.

There are multiple pieces of legislation introduced in the U.S. House and Senate to address different points of state licensing reform. In addition to the Protecting JOBS Act (2018), Representatives Mike Conaway (R-TX) and Lamar Smith (R-TX) introduced the Occupational Licensing Board Antitrust Damages Relief and Reform Act of 2018. This bill seeks to limit private antitrust damages against state licensing board members while proposing a few other modest reforms to board operations. It establishes licensing board requirements for legislative protection, including requirements for receiving a license and a standard of practice for licensees. It also states the board must prove the occupation needs to be licensed, such that unlicensed practitioners could lead to harm and endanger the health, safety, and welfare of the public. The occupation must also be licensed in 40 or more states or the licensing board implements a sunset review process for occupations not widely regulated by states. The legislation creates a set of standards and operational guidelines for aggrieved parties to have their case heard before an occupational licensing board (Occupational Licensing Board Antitrust Damages Relief and Reform Act, 2018).

State licensing reform is expected to continue to be a topic of interest into the 116th Congress convening in January 2019 with an additional focus on incorporating it into criminal justice reform.

\section{Student Loan Defaults}

The practice of suspending or revoking a professional license due to the licensee's student loan repayment status is being called into question at both the state and federal level. It is estimated that by 2023, 40\% of borrowers may default on their student loans (ScottClayton 2018). In today's occupational licensure climate it is possible that many of those in default may require a license to practice their profession (Cottle, 2017). Dating back to the passage of the Higher Education Act of 1965, states have assisted lenders in collecting on loans by revoking or suspending occupational licensures for those who have defaulted (Silver-Greenberg et. al., 2018).

At the national level, Senator Marco Rubio (R-FL) and Senator Elizabeth Warren (D-MA) introduced the Protecting Job Opportunities for Borrowers (Protecting JOBs) Act. Representative Ferguson (R-GA) and representative David Cicilline (D-RI) introduced a companion bill in the House. The Protecting JOBs Act would prevent states from suspending, revoking, or denying state licenses, if a licensee defaults on his or her federal student loans. If the legislation passes, it would take effect in two years to give states time to comply with the change. The legislation would also provide for injunctive relief for aggrieved individuals by allowing them to bring a civil action in a U.S. District Court against "an individual State officer in the officer's official capacity" (Protecting JOBs Act, S.B. 3065, 2018).

In the 1980s, Illinois and Texas led enactment of policies to revoke or suspend licenses due to loan defaults. However, Illinois has moved to reverse the policy in the 2018 legislative session and several other states followed suit with legislation or plans for legislation in the 2019 legislative session.

S22 Journal of Nursing Regulation 


\section{SUPPORT for Patients and Communities Act}

Members of the House Committee on Energy and Commerce and the House Committee on Ways and Means introduced H.R. 6, the Substance Use-Disorder Prevention that Promotes Opioid Recovery and Treatment (SUPPORT) for Patients and Communities Act. This is a combination of multiple individual opioid and substance abuse legislation proposed by members of both committees. Provisions include telehealth regulation, which allows the Secretary of Health and Human Services to waive specified Medicare telehealth requirements for opioid use disorder. The Act was signed into law in October 2018. (SUPPORT for Patients and Communities Act, 2018).

The SUPPORT for Patients and Communities Act addresses the need for additional flexibility for medication-assisted treatment for opioid use disorder. It increased the number of patients a qualified practitioner can treat to 275 . It makes permanent nurse practitioners' ability to prescribe medicated-assisted treatment by amending the Controlled Substances Act. This legislation also allows CNSs, CNMs and CRNAs to obtain a data waiver and prescribe for a period of five years beginning on October 1, 2018 (SUPPORT for Patients and Communities Act, 2018).

There are multiple provisions that address telehealth, including allowing the Secretary of Health and Human Services to waive geographical requirements for individuals to receive substance abuse disorder treatment while still enforcing state licensing laws. Also, CMS is required to issue guidance on how states can receive federal reimbursement for services and treatments via telehealth. This legislation also requires the Drug Enforcement Agency to issue a final rule on when providers are eligible to prescribe control substances via telehealth (SUPPORT for Patients and Communities Act, 2018).

\section{Regulatory Implications}

- BONs should be mindful not to over-regulate the profession as seen in other professions since there is legislative interest in decreasing rules and regulations.

- BONs should review their policies/procedures and board actions for possible anti-trust issues.

- BONs should remember the importance of nursing licensure as a public safety measure and eliminate rules/regulations and any aspect of the law not related to public protection.

- BON staff should have data and talking points ready and be able to address the necessity of nursing licensure and the need for regulatory oversight by the BON.

\section{Social Issues Affecting Nursing and Regulation}

Several social issues are expected to impact nursing in 2019 and are reviewed below. Among them are the nation's continued struggle with opioid use and how nursing can help address the misuse. How nursing can help care for patients who use cannabis medically or as self-treatment also continues to affect the profession. Evolving approaches by pharmaceutical manufacturers to sell their products may cross the lines of appropriate, clinical nursing practice. Additionally, healthcare settings are realizing they are not immune to the impact of social movements related to sexual misconduct and abuse have in the workplace.

\section{Update on the Opioid Epidemic}

By the mid-and late-1970s, when Percocet and Vicodin came on the market, doctors had long been taught to avoid prescribing highly addictive opioids to patients. But a study conducted by Jane Porter and Dr. Hershel Jick of 11,882 patients treated with narcotics changed this. They wrote: "the development of addiction is rare in medical patients with no history of addiction." Jick told the Washington Post in 1977 that less than 1\% of patients he studied died from a reaction to the drugs: "I think very serious adverse reactions are about as infrequent as one could possibly expect given the enormous amount of exposure to drugs." (Moghe, 2016).

Speaking on opioids to the New England Journal of Medicine in March 2016, Dr. Tom Friedan, Director of the Centers for Disease Control and Prevention (CDC), stated: "We know of no other medication routinely used for a nonfatal condition that kills patients so frequently" (Moghe, 2016). Data from the Substance Abuse and Mental Health Services Administration's National Survey on Drug Use and Health show, in 2017, 11.1 million people aged 12 years and older misused prescription pain relievers, about 1.7 million people aged 12 years and older had a prescription pain reliever use disorder, and 953,000 people received treatment for the misuse of opioid pain relievers. (Substance Abuse and Mental Health Services Administration, 2018)

The CDC's National Health Statistics indicate there were 63,632 drug overdose deaths in the United States in 2016 (Centers for Disease Control and Prevention [CDC], 2017). Additionally, the rate of drug overdose deaths involving synthetic opioids such as fentanyl, fentanyl analogs and tramadol doubled in 2016 alone (Centers for Disease Control and Prevention, 2017). A National Institute on Drug Abuse analysis found synthetic opioids, such as illicit fentanyl, surpassed prescription opioids as the most common drug involved in U.S. overdose deaths, with nearly half of opioid-related deaths in 2016 involving synthetic opioids (Jones et al., 2018).

Emergency department visits for opioid overdoses increased 30\% nationwide from July 2016 through September 2017, with an increase of $70 \%$ in the Midwest and an increase of 54\% in large cities across 16 states (CDC, 2018a). The Agency for Healthcare 
Research and Quality's (AHRQ's) online statistical resource is the first to provide comparisons of hospitalization rates for substance use at the county level, allowing statistics to be broken down by age group, sex, payer and type of stay, as well as by hospital costs/charges and lengths of stay (Agency for Healthcare Research and Quality [AHRQ], 2018). AHRQ's resource of statistics includes data provided by 32 states and the data illustrates how the impact of substance use varies widely across communities. For example, Owsley County, Kentucky had the highest overall hospitalization rate for substance use with 3,525 hospital stays per 100,000 population. Ringgold County, Iowa, had the lowest rate with 220 stays per 100,000 population (AHRQ, 2018).

The opioid crisis has "led to thousands of lawsuits being filed against doctors, hospitals, pharmacies, and pharmaceutical manufacturers, blaming them for the increase in opioid addiction, overdoses, and drug-related deaths in America" (ConsumerSafety.org, 2018). Some of the allegations include improperly advertising the benefits of opioids without properly informing physicians or patients of the risks including triggering addiction. Others contain allegations against physicians prescribing unnecessary opioids for a condition and continuing to prescribe well after signs of drug abuse. Even pharmacies are included in lawsuits with individuals and surviving families alleging the pharmacy over-distributed and failed to properly monitor and report suspicious prescription patterns (ConsumerSafety.org, 2018). The plaintiffs in the lawsuits vary and include individuals, county, municipal and tribal entities, as well as 30 state attorneys general. Some lawsuits against pharmacies and pharmaceutical companies have resulted in recoveries in the tens of thousands of dollars (ConsumerSafety.org, 2018).

\section{Initiatives Addressing the Opioid Epidemic}

Several initiatives announced in 2018 aimed at preventing and treating opioid addiction. According to an AMA report, the number of physicians certified to provide opioid use disorder buprenorphine in office for treatment of the substance use disorder increased $42.2 \%$ in the past 12 months (AMA, 2018b). The report also notes naloxone prescriptions more than doubled in 2017, from approximately 3,500 to 8,000 prescriptions dispensed weekly. With over 7,000 nurse practitioners authorized to administer medication-assisted treatment (CARA, 2016) and recently passed legislation likely to increase the number of APRNs eligible to do so, individual providers will play an important role in fighting the opioid crisis.

The following tools have been recently released to assist healthcare practitioners in addressing opioid issues:

- The National Institute on Drug Abuse unveiled a scientifically validated online screening tool designed to assess a patient's risk for substance misuse and substance use disorder and to assist healthcare providers with prevention and treatment strategies (National Institute on Drug Abuse, 2018).

- The FDA released a blueprint for opioid prescriber education with training content that pharmaceutical manufacturers are required to make available to prescribers. Content includes information on acute and chronic pain management, safe use of opioids or other nonopioid or non-drug treatments, as well as material on addiction medicine and opioid use disorders (Federal Drug Administration, 2018).

- The National Academy for State Health Policy published a new brief that discusses the Screening, Brief Intervention, and Referral to Treatment (SBIRT) and Medication-assisted Treatment evidence-based interventions (Townley and Dorr, 2017).

Prescription drug monitoring programs and electronic prescribing continue to be useful tools in identifying overprescribing practices. According to the AMA (AMA, 2018b), PDMP registration and use continues to rise with a $121 \%$ increase in the number of times healthcare providers nationwide accessed state PDMPs from 2016 to 2017. Nebraska became the first state to require all prescription drugs be logged into their PDMP database daily, which allows prescribers and pharmacists to access a patient's complete medication history (Nebraska DHHS, 2018). Colorado, Hawaii, Iowa, Idaho, and Oregon also passed bills requiring prescribers to participate in PDMPs (S.B. 18-022, Colo. 2018; S.B. 2646, Hawaii. 2018; H.B. 2377, Iowa 2018; H.B. 4143, Ore. 2018). Nevada passed a bill in 2018 that fast-tracks the collection of overdose death data in the state and flags excessive dispensing of powerful painkillers (A.B. 474, Nev. 2017). California, meanwhile, authorized their justice department to share PDMP information across state lines (A.B. 1751, Calif. 2018).

Other bills focused on educating both prescribers and patients. Indiana and Illinois concentrated on requiring continuing education on opioids as a criterion for licensure renewal (S.B. 225, Ind. 2018; S.B. 2777, Ill. 2018). Maryland now requires prescribers to discuss the risks and benefits of opioids with patients before beginning a treatment (S.B. 522, Md. 2018). South Carolina centered on students, requiring health profession education programs to incorporate coursework on controlled substances (S.B. 302, S.C. 2018).

South Carolina's education focus is supported by recent evidence. Although nurses are on the front lines of the opioid epidemic, surveys indicate little curricular change in the type and amount of alcohol and other drug use content in the last 4 decades (Finnell, et al, 2018). The authors note the emergence of the opioid crisis emphasized the need to better inform nursing students about addiction and offered potential solutions. Despite the concern of an already crowded curriculum, a suggested four-phase process to add substance use disorder content into a prelicensure nursing curriculum and a master's level advanced practice nursing curriculum includes developing the knowledge and skills of faculty, planning and development of curriculum modules, implementing the curriculum changes, evaluation and revision. The authors believe these "widespread curricular changes are needed to close the education-practice gap in this area" (Finnell, et al, 2018). 
At a Minnesota university, a comprehensive education strategy was implemented and evaluated in two prelicensure nursing programs to improve nursing students' knowledge, skills, and attitudes about substance use disorder (Stewart and Mueller, 2018). Several other universities have also introduced curricula that include the nursing care of a patient with an opioid addition or overdose (Bird, 2018).

Additional education to nursing management can assist in identifying nurses who need help with their substance use disorder. Unsafe nurses or those suspected of diversion or drug use who are simply terminated without a report to the BON can continue to compromise patient safety by moving to another unsuspecting employer. As part of the nursing profession's emphasis on patient safety, it's critical that employers address this problem by reporting or referring nurses so they can receive the treatment and support they need.

\section{Medical and Recreational Marijuana Use}

The use of medical or recreational cannabis raises evolving public health, nursing practice, science, legal, education, ethical, and social issues. Of significance, there is a contradiction between the federal law classifying cannabis as a Schedule I Controlled Substance and various states legalizing its use medically and/or recreationally. This federal classification prevents open and unlimited research on cannabis. As a result, research on the efficacy of cannabis for treatment of certain medical conditions is limited and lacking. Specifically, the research has not definitively specified indications, dosage, route, safety, adverse effects, and long-term effects of cannabis. Without evidence that is scientifically rigorous, statistically reportable, and based on patient populations, nurses face increasing challenges concerning medical cannabis.

To address the lack of guidelines for nurses when caring for individuals utilizing cannabis, the NCSBN Board of Directors appointed members to the Medical Marijuana Nursing Guidelines Committee. To create the requested guidelines and recommendations for education and care, a review of the relevant statistics, current legislation, scientific literature, and clinical research on cannabis as a therapeutic agent was completed.

The Medical Marijuana Nursing Guidelines Committee review found there is moderate- to high-quality evidence for effective treatment with cannabis for the following conditions: (a) cachexia, (b) chemotherapy-induced nausea and vomiting, (c) pain (from cancer or rheumatoid arthritis), (d) chronic pain (from fibromyalgia), (e) neuropathies (from HIV/AIDS, multiple sclerosis, or diabetes), and (f) spasticity (from multiple sclerosis or spinal cord injury). Cannabidiol oil in FDA-approved formulations show further efficacy for reduction of seizure frequency (Dravet syndrome and Lennox-Gastaut syndrome). These findings and other important practice implications were published recently in the Journal of Nursing Regulation as the NCSBN National Nursing Guidelines for Medical Marijuana (NCSBN, 2018e).

Nurses need practical information to care for the increasing number of patients who use cannabis via a medical marijuana program or who self-administer cannabis as a treatment for various symptomatology or for recreational purposes. As noted, evidence for cannabis use in described conditions is limited by inadequate study and limited legal availability of cannabis for research purposes. Statutory authorization of cannabis use for certain conditions has been influenced by advocacy, and as a result, some qualifying conditions are present in statutes without evidence of their effect. Regardless of existing evidence, individuals are using cannabis and nurses will care for these patients. The studies and literature should inform nursing practice that represents the best interests of the patient.

The implications of cannabis use includes six principles of essential knowledge for the nurse. Nurses should have:

- A working knowledge of the current state of legalization of medical and recreational cannabis use.

- A working knowledge of the jurisdiction's medical marijuana program.

- An understanding of the endocannabinoid system, cannabinoid receptors, cannabinoids, and the interactions between them.

- An understanding of cannabis pharmacology and the research associated with the medical use of cannabis.

- Ability to identify the safety considerations for patient use of cannabis.

- An understanding of how to approach the patient without judgment regarding the patient's choice of treatment or preferences in managing pain and other distressing symptoms (NSCBN, 2018e).

These principles are the foundation for specific guidelines, which include: (a) nursing care of the patient using medical marijuana, (b) medical marijuana education in pre-licensure nursing programs, (c) medical marijuana education in APRN nursing programs, and (d) APRNs certifying a medical marijuana qualifying condition (NSCBN, 2018e).

A new law in Illinois, the Alternatives to Opioids Act (Illinois General Assembly, 2018), encourages patients who might otherwise use opioids to consider marijuana to manage their pain. It is the first law in the United States to explicitly suggest marijuana could be used as a substitute for opioids. The law creates a pilot program that allows patients 21 years of age or older to obtain a physician's certification stating they have a condition for which an opioid could be prescribed, allowing the patient to receive medical cannabis for up to 90 days. It also eliminates fingerprinting, lifts the prohibition against individuals with a criminal history, and allows temporary access to marijuana while Illinois completes the full certification for each user. The law mandates that patients still register with the state's cannabis tracking system, which records every transaction at a dispensary. 


\section{Nurse Ambassadors}

An increasing number of lawsuits filed by whistleblowers accuse large pharmaceutical manufacturers of using nurses to illegally market their products. Guised as providers delivering care to patients using the manufacturer's products, the lawsuits allege companies such as Eli Lilly and Company, AbbVie Inc, Gilead, Bayer Corporation, Amgen Inc, and AstraZeneca, use nurses to keep patients on the drug even when there may be alternatives available (Silverman et. al., 2018). In the filing against AbbVie Inc., California claims AbbVie hires "nurse ambassadors" who "provide unbalanced information: trained to tout the good while at the same time instructed on methods to avoid directly answering patient questions on the bad, even those pertaining to Humira's serious and important side effects" (State of Calif. v. AbbVie, 2018). AbbVie hires nurse ambassadors on behalf of prescriber officers to provide patient care and assist with insurance authorization and paperwork among other tasks. The lawsuit alleges that as long as a physician prescribes Humira, the physician's office receives these valuable services (State of Calif. v. AbbVie, 2018). The case against Eli Lilly alleges the use of free nursing services to "induce healthcare providers to prescribe the drug maker's insulin products Humalog and Humulin" (Syrop, 2017).

In both the AbbVie and Eli Lilly examples, the practices blur the lines between providing clinical nursing services and promoting the sale of a drug (Sagonowsky, 2017). Patients who were prescribed Humira often received home visits from nurses, providing care and trainings on administering injections (Davio, 2018). These services "alleviated burdens on prescribers' practices in exchange for selecting Humira from a range of available treatments" (Davio, 2018). The suits claim the nurses are accountable to the companies, not the patients or prescribers. A practice nursing professor Elissa Ladd of the Massachusetts General Hospital Institute of Health Professions finds: [this adds a] "dark layer to our whole system, because we don't really know what they're doing” (Silverman et. al., 2018).

\section{Nurses and \#MeToo and TIME'S UP Movements}

As 2017 ended, TIME magazine acknowledged a new cultural era by naming as its Person of the Year 'The Silence Breakers', the women who spoke out about their experiences with sexual assault by leaders in business, politics, and entertainment. These women represented the beginnings of the Me Too and TIME'S UP movements, which call for an end to the prevalence and normalization of sexual assault and harassment, particularly in the workplace (Felsenthal, 2017). The movements have shaped culture and policy in surprising ways throughout 2018, and their influence continues to strengthen, proving likely to change the cultural landscape for many years to come.

Many professional fields have examples of influential figures whose actions have been exposed by the movement. In the healthcare field, Olympic women's gymnastics physician Larry Nassar is the most notable. The most fundamental Me Too movement changes in healthcare will likely begin to evolve over the next few years.

In June 2018, Medscape released the results of a survey of 6,200 providers (physicians, nurses, nurse practitioners, and physician assistants) across the United States to determine the current state of sexual misconduct in healthcare. The results were divided into physician and non-physician respondents. Eleven percent of nurses, nurse practitioners, and physician assistants reported having experienced misconduct in the past 3 years, and $14 \%$ witnessed it. When divided by gender, women were twice as likely as men to have experienced sexual misconduct; however, men in healthcare were nearly twice as likely to witness it happening to someone else. Four percent of male respondents indicated they had been accused of such misconduct while no female respondents reported being accused (Kane \& Levy, 2018). Nurses reported that, although 33\% of the incidents were perpetrated by physicians and about 20\% from other nurses, the majority were from people who fit in neither category, such as administrators or patients. In over $60 \%$ of cases, the victim did not report the misconduct, most commonly out of fear that it would be trivialized, and/or no action would be taken. In fact, these were the two most common outcomes of an incident being reported. Only $25 \%$ of incidents were investigated (Kane \& Levy, 2018).

In February 2018, citing its strong support for the TIME'S UP movement, ANA released a statement emphasizing the elimination of sexual harassment. ANA's initiative includes calling on nurses and employers to take a zero-tolerance pledge against workplace abuse and plans to convene a panel of experts to address barriers to reporting abuse against nurses (American Nurses Association, 2018). The New York State Nurses' Association also revised and reissued their position statement on sexual harassment in 2018, noting the toll that such harassment takes on both the individual nurse and patient care overall (New York State Nurses' Association, 2018).

\section{Regulatory Implications}

- The state PDMP remains an important method for monitoring patient use of opioids and should be used by APRNS. BONS can also use the PDMP to monitor practitioner complaints.

- There is an increased focus on opioid education. Nursing programs are establishing curricular changes and some BONs are requiring nurses to take continuing education related to substance use disorder for license renewal.

- NCSBN National Nursing Guidelines for Medical Marijuana should serve as a resource for facilities, APRNs, and educators grappling with questions about caring for patients taking marijuana. Guidelines for dealing with complaints to the BON regarding nurses who have tested positive for marijuana have also been developed.

- BONS should pay attention to the pharmaceutical manufacturer practice of hiring nurse ambassadors who may provide subjective care and information. 
- BONs may likely see an increase in complaints related to sexual misconduct in the coming years and will need to know how to appropriately address them.

\section{International Issues The 2018 Ebola Outbreak}

In August of 2018, the Ministry of Health of the Democratic Republic of the Congo alerted WHO of an Ebola virus disease (EVD) outbreak in the provinces of North Kivu and Ituri. These provinces are nearly 800 miles away from the Equateur province, where there was another reported outbreak in May 2018 (CDC, 2018b). As of November 2018, there were 294 confirmed cases of Ebola and 170 deaths (WHO, 2018a). In contrast to the 2014-2016 outbreak, the pattern of the 2018 outbreak is scattered and has spread to larger cities (Doctors Without Borders, 2018).

Given the efficiency of air travel, an Ebola outbreak anywhere in the world can have implications for nursing in the United States. The last outbreak in West Africa (2014-2016) brought the virus to the United States and stirred major concern across the country due to the lack of preparation to handle exposure, the severity of the illness, and the absence of facility policy and procedures. While concerns loom and vigilance is paramount, the early stages of development and testing commenced only in the final days of the 2014-2016 epidemic (Howard, 2018). In 2019, vaccine-related treatments for EVD are more readily available. Five developmental drugs are now available (Favipiravir, Remdesivir [GS5734], REGN3470-3471-3479, ZMapp, and mAb114) (Doctors Without Borders, 2018) and the availability of developmental drugs and on-site testing means people who test positive can be offered these treatments within 24 hours of confirmation (Doctors Without Borders, 2018). For the current outbreak, international relief organizations are putting into place, "extremely rigorous safety procedures to ensure that no health workers are exposed to the virus through contaminated material from patients or medical waste infected with Ebola" (Doctors Without Borders, n.d.). The National Institutes of Health has an openlabel clinical trial "Pre-Exposure Prophylaxis in Individuals at Potential Occupational Risk for Ebola Virus Exposure" or "PREPARE," to vaccinate adult volunteers (including deploying HCWs and other responders) against Ebola.

As with any epidemic, healthcare workers are at high-risk as they provide care for patients with infectious diseases (WHO, 2018b). Although there have been no confirmed U.S. cases during the current outbreak, regulators should be prepared for issues that occurred during the 2014-2016 outbreak. These include nurses potentially refusing to take care of an affected patient. BONs should clearly define the criteria for patient abandonment and make it available to institutions in their state. Collaboration and communication during any crisis is the key to prevention as well as minimizing bad outcomes.

\section{Summary and Conclusions}

- The LPN/LVN workforce is gradually decreasing. This may not only have serious impact on long-term care, it may perpetuate the development and/or growth of new roles of assistive personnel. Range of practice and responsibilities of these individuals, along with who can delegate, may be looming issues for the near future.

- A plethora of evidence emerges on an annual basis demonstrating that APRNs can fill the gaps in primary care caused by a maldistribution of providers and a shortage of physicians. APRNs need to continue to pursue legislative activities to advance scope of practice along with other elements of the APRN Consensus Model.

- More nurses than ever before partake in some type of telehealth nursing care. BONs should be reminding state constituents that practice is where the patient is and if practice is outside the state another license is required. While remote patient monitoring may not necessarily be improving care, it is showing promise in certain areas and will be a solution for patients living a distance from their provider. Expect that this can also be done across an international border. BONs need to reinforce this message as the possibility of outsourcing telehealth practice to nurses living outside the United States becomes a reality.

- There is a strong movement in the direction of the DNP as a replacement for the Master of Science in Nursing degree and as a requirement for advanced practice registered nurses. The questions BONs should be asking is what is the value added by requiring a doctoral degree as entry to practice, compared to the current master's degree requirement? What evidence is there that DNP prepared nurses are better clinicians or more importantly, safer and more competent, than master's prepared nurses?

- The faculty shortage and the diminishing number of clinical sites for student clinical experience remain at the top of issues facing educators.

- The issues of licensure, antitrust and deregulation will remain as issues of interest to legislators in 2019. BONs should be mindful of these issues and not over-regulate in their state.

- Marijuana use will continue to be a growing issue for BONs as more and more states legalize it for both medical and recreational use. BONs should refer to NCSBN's new Guidelines for BONs for assistance with nursing complaints. 
- Of interest this year was the passage of New York's BSN in 10 bill. This passed after years of attempts in the state legislature. Expect other states such as New Jersey to consider this type of legislation in the near future.

- BONs should review and update existing guidance documents in anticipation of emerging issues and trends that may affect them in future years. To review recent changes and revisions by BONs, see Appendix A, Board of Nursing Position and Advisory Statements. 


\section{References}

A.B. 1751, 2017-2018 Reg. Sess. (Calif. 2018)

A.B. 474. (Nev. 2017).

Adams, E. K., \& Markowitz, S. (2018). Improving efficiency in the health-care system: Removing anticompetitive barriers for advanced practice registered nurses and physician assistants, BROOKINGS. Retrieved from https://www.brookings.edu/research/improvingefficiency-in-the-health-care-system-removing-anticompetitivebarriers-for-advanced-practice-registered-nurses-and-physicianassistants/

Agency for Healthcare Research and Quality. (2018a). Healthcare cost and utilization project. Retrieved from https://www.ahrq.gov/data/hcup/ index.html

American Association of Colleges of Nursing. (2018a). DNP fact sheet. Retrieved from: https://www.aacnnursing.org/News-Information/ Fact-Sheets/DNP-Fact-Sheet

American Association of Colleges of Nursing. (2018b). The preferred vision of the professoriate in baccalaureate and graduate nursing programs. Journal of Professional Nursing. 34, 3-4.

American Association of Nurse Practitioners. (2018, September 26). AANP statement on release of final opioid legislation. Retrieved from https://www.aanp.org/news-feed/aanp-statement-on-release-offinal-opioid-legislation

American Hospital Association. (2018a). FCC seeks comments on proposal for connected care pilot program. Retrieved from https://www. aha.org/news/headline/2018-08-02-fcc-seeks-comments-proposalconnected-care-pilot-program

American Hospital Association. (2018b). Fact sheet: The Resident Physician Shortage Reduction Act of 2017. Retrieved from https://www. aha.org/factsheet/2018-04-02-factsheet-resident-physician-shortagereduction-act-2017

American Medical Association. (2018a, April 9). AMA, Google launch health care interoperability \& innovation challenge. Retrieved from https://www.ama-assn.org/ama-google-launch-health-careinteroperability-innovation-challenge

American Medical Association. (2018b, August). Physician's progress to reverse the nation's opioid epidemic: American Medical Association opioid task force 2018 progress report. Retrieved from http://www. end-opioid-epidemic.org/wp-content/uploads/2018/05/AMA2018OpioidReport-FINAL-updated.pdf

American Nurses Association. (2018, February 1). ANA addresses sexual harassment as part of the \#EndNurseAbuse initiative. Retrieved from https://www.nursingworld.org/news/news-releases/2018/anaaddresses-sexual-harassment-as-part-of-endnurseabuse-initiative/

Arizona Board of Nursing. (2018). Military veterans with a healthcare designation seeking to sit for the NCLEX-PN. Retrieved from https:// www.azbn.gov/media/2930/ao-military-veterans-with-a-healthcaredesignation-seeking-to-sit-for-nclex-5-2018.pdf

Arndt, R. Z. (2018, September 22). The internet of things extends healthcare into the home. Modern Health Care. Retrieved from http://www. modernhealthcare.com/article/20180922/TRANSFORMATION01/ 180929992?utm_source $=$ modernhealthcare\&utm_medium $=$ email\&utm_content $=$ 20180922-TRANSFORMATION01180929992\&utm_campaign $=$ dose

Ashrafian, H., Clancy, O., Grover, V., \& Darzi, A. (2017). The evolution of robotic surgery: Surgical and anaesthetic aspects. BJA: British Journal of Anaesthesia, 119(suppl.1), i72-i84.
Association of American Medical Colleges. (2018). The complexities of physician supply and demand: Projections from 2015 to 2030. Retrieved from https://aamc-black.global.ssl.fastly.net/production/media/filer_ public/85/d7/85d7b689-f417-4ef0-97fb-ecc129836829/ aamc_2018_workforce_projections_update_april_11_2018.pdf

Association of American Medical Colleges. (2018). The complexities of physician supply and demand: Projections from 2015 to 2030. Retrieved from https:/aamc-black.global.ssl.fastly.net/production/ media/filer_public/85/d7/85d7b689-f417-4ef0-97fb-ecc129836829/ aamc_2018_workforce_projections_update_april_11_2018.pdf

Association of State and Provincial Psychology Boards. (n.d.) PSYPACT legislative updates. Retrieved from https://www.asppb.net/mpage/ legislative

Badger Institute, (2017, November 27). Occupational licensing reforms signed into law. Badger Institute. Retrieved from https://www.badgerinstitute.org/News/2017-2018/Occupational-licensing-reformssigned-into-law.htm

Bean, R. (2018, Aug. 5). Will blockchain transform healthcare? Forbes. Retrieved from https://www.forbes.com/sites/ciocentral/2018/08/05/ will-blockchain-transform-healthcare/\#70c059d2553d

Bhatti, Y., del Castillo, J., Olson, K., \& Darzi, A. (2018, March 2). Putting humans at the center of health care innovation. Harvard Business Review. Retrieved from https:/hbr.org/2018/03/putting-humans-atthe-center-of-health-care-innovation

Bill Track 50. (2018). Paul Mosley - (R) Arizona. Retrieved from https:/ www.billtrack50.com/LegislatorDetail/22438

Bird, G. (2018, April 11). Confronting the opioid crisis - Nursing colleges add curricula to deal with a growing public health problem. Inside Higher $E d$. Retrieved from https://www.insidehighered.com/ news/2018/04/11/nursing-schools-changing-curricula-addressopioid-epidemic

Blockgeeks. (2018). What is blockchain technology? A step-by-step guide for beginners. Retrieved from https://blockgeeks.com/guides/whatis-blockchain-technology/

Bousfield, Chrissie. (2008). A phenomenological investigation into the role of the clinical nurse specialist. Journal of Advanced Nursing. 25(2), 245-256 https://doi.org/10.1046/j.1365-2648.1997.1997025245.x.

Brockopp, D. Y. (2018). Nursing research: A conundrum. JONA, 48(5), 231-232.

Broome, M. E. \& Fairman, J. (2018). Changing the conversation about doctoral education in nursing. Nursing Outlook, 66, 217-218.

Browne, R. (2018, August 17). Tech firms say A.I. can transform health care as we know it. Doctors think they should slow down. CNBC. Retrieved from https://www.cnbc.com/2018/08/17/healthcare-andai-doctors-warn-on-the-pace-of-technological-change.html

Buerhaus, P. (2018). Nurse Practitioners: A solution to America's primary care crisis. American Enterprise Institute. Retrieved from http://www. aei.org/publication/nurse-practitioners-a-solution-to-americasprimary-care-crisis/

Buerhaus, P. I., Staiger, D. O., \& Auerbach, D. I. (2000). Implications of an aging registered nurse workforce. JAMA, 283(22), 2948-2954.

Camacho Torres, Mary (2018, February 9). New law allows better access to health care. The Guam Daily Post. Retrieved from https://www. postguam.com/forum/featured_columnists/new-law-allows-betteraccess-to-health-care/article_5b132b02-0c96-11e8-a53417c4dd7ff19d.html 
Centers for Disease Control and Prevention. (2017). Drug overdose deaths in the United States, 1999-2016. Retrieved from https://www.cdc. gov/nchs/data/databriefs/db294.pdf

Centers for Disease Control and Prevention. (2018a). Opioid overdoses treated in emergency departments. CDC Vitalsigns. Retrieved from https://www.cdc.gov/vitalsigns/pdf/2018-03-vitalsigns.pdf

Centers for Disease Control and Prevention. (2018b). 2018 Eastern Democratic Republic of the Congo. Retrieved from https://www.cdc.gov/ vhf/ebola/outbreaks/drc/2018-august.html

Centers for Medicare \& Medicaid Services. (2018). Fact sheet. Proposed policy, payment, and quality provisions changes to the Medicare physician fee schedule for calendar year 2019. Retrieved from https:// www.cms.gov/newsroom/fact-sheets/proposed-policy-payment-andquality-provisions-changes-medicare-physician-fee-schedulecalendar-year-3

Chan, K. (2018, August 18). Birth control app highlights emerging health tech market. Denver Post. Retrieved from https://www. denverpost.com/2018/08/18/natural-cycles-birth-control-app/

Choinski, C., Hamer, C., Hamm, S., Macdonald, M., \& Nelson, P. (1978). Sound off! Playing with the entry requirement: A game we can't afford. $R N, 41(12), 27-32$.

Chokshi, D. A., Cohen, L. (2018). Progress in primary care - From AlmaAta to Astana. JAMA, 320(19), 1965-1966. Retrieved from https:// jamanetwork.com/journals/jama/fullarticle/2715579

Comprehensive Addiction and Recovery Act (CARA), S. 524, 114th Cong. (Retrieved from); 2016

https://www.congress.gov/bill/114th-congress/senate-bill/524/text

ConsumerSafety.org. (2018). Opioid lawsuits. ConsumerSafety.org. Retrieved from https://www.consumersafety.org/legal/opioidlawsuits/

Cottle, M. (2017, August 13). The onerous, arbitrary, unaccountable world of occupational licensing. The Atlantic. Retrieved from https:// www.theatlantic.com/politics/archive/2017/08/trump-obamaoccupational-licensing/536619/

Council on Accreditation. (n.d.). COA Position statements. Retrieved from https://www.coacrna.org/about/Pages/COA-PositionStatements.aspx

Davio, K. (2018, September 19). Lawsuit: AbbVie used kickbacks and nurse ambassadors to boost Humira sales. The Center for Biosimilars. Retrieved from https://www.centerforbiosimilars.com/news/lawsuitabbvie-used-kickbacks-and-nurse-ambassadors-to-boost-humira-sales

Defense Advanced Research Projects Agency. (n.d.) https://www.darpa. mil/about-us/timeline/tcp-ip

Densford, F. (2018, January 23). Leaf Healthcare touts reduced pressure injuries in Leaf wearable sensor study. Mass Device. Retrieved from https://www.massdevice.com/leaf-healthcare-touts-reduced-pressureinjuries-leaf-wearable-sensor-study/

Doctors Without Borders/Medicins Sans Frontieres (MSF). (2018, Oct 25). DRC: What we know about the latest Ebola outbreak. Retrieved from https://www.doctorswithoutborders.org/what-we-do/newsstories/story/drc-what-we-know-about-latest-ebola-outbreak

Doctors Without Borders/Medicins Sans Frontieres (MSF). (n.d.). MSF has intervened in almost all recent epidemics of Ebola, one of the world's deadliest diseases. Retrieved from https://www. doctorswithoutborders.org/what-we-do/medical-issues/ebola

Elpern, E. \& Disch, J. (2018). Retired nurse volunteers: A valuable - and untapped - resource. AJN. 118(8), 60-63.
eVisit (2018). History of telemedicine. (2018, May 25). Retrieved from https://evisit.com/resources/history-of-telemedicine/

Faiola, A., Papautsky, E. L., \& Isola, M. (2018). Empowering the aging with mobile health: A mhealth framework for supporting sustainable healthy lifestyle behavior. Current Problems in Cardiology. Retrieved from https://www.sciencedirect.com/science/article/pii/ S0146280618300823

Fang, D. \& Htut, A. M. (2009) Special survey of AACN membership on vacant faculty positions for academic year 2008-2009. Retrieved from: https://www.aacnnursing.org/Portals/42/News/Surveys-Data/ vacancy08.pdf

Farr, C. (2018a). Amazon, Alphabet, Microsoft and other tech giants want to fix one of the most broken things about health care. CNBC. Retrieved from https://www.cnbc.com/2018/08/13/amazonalphabet-microsoft-health-data-pledge.html

Federal Drug Administration. (2018). FDA's opioid analgesic REMS education blueprint for health care providers involved in the treatment and monitoring of patients with pain. Retrieved from http://www. njha.com/media/494433/OpioidAnalgesicREMSEduBlueprint.pdf

Federal Trade Commission (FTC). (2018, September 24). Policy perspectives: Options to enhance occupational licensure portability. Retrieved from https://www.ftc.gov/reports/options-enhanceoccupational-license-portability

Feeg, V. \& Mancino, D. J. (2018a). Interim report for NSNA annual survey of new graduates: Graduation by spring/summer 2018. Unpublished report.

Feeg, V. \& Mancino, D.J. (2018b). New graduates first jobs and future plans: Debt, employers, and education prospects. Deans Notes, 40(1), $1-5$.

Felsenthal, E. (2017, December 18). The choice: Time's editor-in-chief on why the silence breakers are the person of the year. Time. Retrieved from http://time.com/time-person-of-the-year-2017-silencebreakers-choice/

Finnell, D. S., Savage, C. L., Hansen, B.R., Sanchez, M., White, K.M., Johnson, J.A., \& Seale, J.P. (2018). Integrating substance use content in an "overcrowded" nursing curriculum. Nurse Educator, 43(3), 128131.

Flannery, D. B. (2018). Challenges and opportunities for effective delivery of clinical genetic services in the US healthcare system. Current Opinion in Pediatrics, 30(6), 740-745.

Florida Board of Nursing. (2018). The Don Hahnfeldt Veteran and Military Family Opportunity Act. Retrieved from http://www.myfloridahouse. gov/Sections/Documents/loaddoc.aspx?FileName=_h0029er. docx $\&$ Document Type $=$ Bill $\&$ BillNumber $=0029 \&$ Session $=2018$

Fowler, S. B., Rosado, C. A., Jones, J., Ashworth, S., \& Adams, D. (in press). Novel use of a nurse-led telemedicine team in acute stroke: A retrospective review of the impact on a regional health care system. Journal of Emergency Nursing.

Fritz, E. (2018). Transition from clinical educator to educator roles in nursing: An integrative review. Journal for Nurses in Professional Development, 34(2), 67-77.

Fröhlich, H., Balling, R., Beerenwinkel, N., Kohlbacher, O., Kumar, S., Lengauer, T., ... Zupan, B. (2018). From hype to reality: Data science enabling personalized medicine. BMC Medicine, 16(1), 150.

Gamache, R., Kharrazi, H., \& Weiner, J. P. (2018). Public and population health informatics: The bridging of big data to benefit communities. Yearbook of Medical Informatics, 27(01), 199-206. 
Georgia BON. (2018). Licensure by examination as a registered nurse. graduates of nontraditional nursing education programs. Retrieved from http://sos.ga.gov/PLB/acrobat/Forms/38\%20Application $\% 20$ -\%20Licensure $\% 20$ by $\% 20$ Examination $\% 20$ for $\% 20$ Graduates $\% 20$ of $\% 20$ Nontraditional $\% 20$ Nursing $\% 20$ Programs $\% 23$.pdf

Greene, J. (2018, September 9). Telemedicine meets artificial intelligence at bedside. Crain's Detroit Business. Retrieved from http://www. crainsdetroit.com/health-care/telemedicine-meets-artificialintelligence-bedside

H.B. 1245, 2018 Reg. Sess. (Ind. 2018).

H.B. 1337, 2018 Legislature, 2018 Reg. Sess. (Fla. 2018)

H.B. 144, 2018 Reg Sess. (La. 2018).

H.B. 2197, 53rd Legislature, 2nd Reg. Sess. (Ariz. 2018).

H.B. 2377, 2018 Reg. Sess. (Iowa. 2018).

H.B. 4143, 2018 Reg. Sess. (Ore. 2018).

H.B. 748. 2018 Reg. Sess. (La. 2018).

Hackey, R. B., Grasso, V., LaRochelle, M., \& Seaver, K. (2018). Rethinking the shortage of primary care physicians. Journal of the American Academy of PAs, 31(6), 47-50.

Harrison, K. (2018, August 16). The next big thing in health technology is humans (and this company is leading the way). Forbes. Retrieved from https://www.forbes.com/sites/kateharrison/2018/08/16/thenext-big-thing-in-health-technology-is-humans-and-this-companyis-leading-the-way/\#2b791b963c57

Health Resources and Services Administration. (2017). Supply and demand projections of the nursing workforce: 2014-2030. Retrieved from https:// bhw.hrsa.gov/sites/default/files/bhw/nchwa/projections/NCHWA_ HRSA_Nursing_Report.pdf

Health Resources and Services Administration. (2018). Long-term services and supports: Nursing workforce demand projections: 20152030. Retrieved from https://bhw.hrsa.gov/sites/default/files/bhw/ nchwa/projections/hrsa-ltss-nursing-report.pdf

Heath, S. (2018). NPs, PAs could reduce primary care physician shortage nearly $70 \%$. Patient Engagement HIT. Retrieved from: https://patientengagementhit.com/news/nps-pas-could-reduce-primary-carephysician-shortage-nearly-70

Hernandez, D. \& Greenwald, T. (2018, August 11). IBM has a Watson dilemma. Wall Street Journal. Retrieved from https://www.wsj.com/ articles/ibm-bet-billions-that-watson-could-improve-cancertreatment-it-hasnt-worked-1533961147

Holland, E. (2018, May 25). Telemedicine reinvents the visit to the school nurse. Wall Street Journal. Retrieved from https://www.wsj.com/ articles/telemedicine-reinvents-the-visit-to-the-schoolnurse- 1527259188

Howard, J. (2018, May 29). Ebola outbreak 2018: What's different this time? CNN. Retrieved from https://www.cnn.com/2018/05/29/ health/ebola-outbreak-2018-response-explainer/index.html

Hunsicker, J. \& Chitwood, T. (2018). High-stakes testing in nursing education: A review of the literature. Nurse Educator, 43(4), 183-186.

Illinois General Assembly (2018, August 28) Public Act 100-1114. Retrieved from http://www.ilga.gov/legislation/publicacts/ 100/100-1114.htm

Institute of Medicine (IOM). The future of nursing: Leading change, advancing health. The National Academies Press, Washington, DC; 2011

Interstate Medical Licensure Compact. (2018). The IMLC. Retrieved from https://imlcc.org/
Jessee, M. A. (2018). Pursuing improvement in clinical reasoning: The integrated clinical education theory. Journal of Nursing Education, 57(1), 7-13.

Jiménez-Marrero, S., Yun, S., Cainzos-Achirica, M., Enjuanes, C., Garay, A., Farre, N., \& Comín-Colet, J. (2018). Impact of telemedicine on the clinical outcomes and healthcare costs of patients with chronic heart failure and mid-range or preserved ejection fraction managed in a multidisciplinary chronic heart failure programme: A sub-analysis of the iCOR randomized trial. Journal of Telemedicine and Telecare, 22(5). https://doi.org/10.1177/1357633X18796439

Jones, C. M., Einstein, E. B., \& Compton, W. M. (2018). Changes in synthetic opioid involvement in drug overdose deaths in the United States, 2010-2016. JAMA, 319(17), 1819-1821.

Kane, L. \& Levy, S. (2018, June 27). Sexual harassment of nurses, NPs, and PAs: Report 2018. Retrieved from https://www.medscape.com/ viewarticle/898152

Kappel, D. (2018, Januaury 19). Enhanced Nurse Licensure Compact (eNLC) Implemented Jan. 19, 2018. Chicago, IL, USA.

Kentucky Press News service. (2016, October 25). Labor cabinet receives $\$ 896,600$ apprenticeship grant. Retrieved from http://www. kentuckynewera.com/news/ap/article_a5370258-9a69-11e6-8774df12839ce7f1.html

Kim, Y., Park, J. E., Lee, B. W., Jung, C. H., \& Park, D. A. (2018). Comparative effectiveness of telemonitoring versus usual care for type 2 diabetes: A systematic review and meta-analysis. Journal of Telemedicine and telecare. https://doi.org/10.1177/1357633X18782599

Krishnan, P. (2018). A philosophical analysis of clinical decision making in nursing. Journal of Nursing Education, 57(2), 73-78.

L.B. 299. 2018 Reg. Sess. (Neb. 2018).

L’Ecuyer, K.M., von der Lancken, S., Malloy, D., Meyer, G. \& Hyde, M. J. (2018). Review of state boards of nursing rules and regulations for nurse preceptors. Journal of Nursing Education, 57(3), 134-141.

Lazarus, D. (2018, August 17). CVS 'video visits' represent a genuine improvement to the healthcare system. Los Angeles Times. Retrieved from http://www.latimes.com/business/lazarus/la-fi-lazarus-cvsvideo-medicine-telehealth-20180817-story.html

Leingang, Rachel. (2018, February 16). Legislature joins push to delicense, deregulate all sorts of professions and jobs. Arizona Capitol Times. Retrieved from https://azcapitoltimes.com/news/2018/02/16/ arizona-doug-ducey-licenses-deregulate-professions/

Leventhal, R. (2018, September 5). Humana to launch digital health and analytics center in Boston. Healthcare Informatics. Retrieved from https://www.healthcare-informatics.com/news-item/analytics/ humana-launch-digital-health-and-analytics-center-boston

Li, Y., Turinetti, M. \& Fang, D. (2018). Special survey on vacant faculty positions for academic year 2018-2019. Unpublished report.

Linn, L., \& Koo, M. (2016). Blockchain for health data and its potential use in health IT and health care related research. Retrieved from https://www.healthit.gov/sites/default/files/11-74ablockchainforhealthcare.pdf

Mahaffey, E. (2002). The relevance of associate degree nursing: Past, present, future. Retrieved from: http://ojin.nursingworld.org/MainMenuCategories/ANAMarketplace/ANAPeriodicals/OJIN/ TableofContents/Volume72002/No2May2002/ RelevanceofAssociateDegree.html

Manchester, J. (2018, August 13). FCC commissioner: Telehealth push is designed to aid low-income Americans. The Hill. Retrieved from https://thehill.com/hilltv/rising/401537-fcc-chief-commissionspush-for-telehealth-is-designed-to-aid-low-income 
Mancino, D. J. (2009). Entry-level positions for new graduates: Real-time dilemma requires real-time solutions. Deans Notes, 31(1), 1-3.

Manetti, W. (2018). Evaluating clinical judgment of prelicensure nursing students in the clinical setting. Nurse Educator, 43(5), 272-276.

MarketWatch. (2018, August 28). Telehealth market is supposed to reach US $\$ 9.50$ billion by 2022. Retrieved from https://www.marketwatch.com/press-release/telehealth-market-is-supposed-to-reach-us950-billion-by-2022-2018-08-28

MarketWatch. (2018, September 7). Global surgical chips market 2027 vision Penetration of technology into healthcare industry boost the market globally - Market research future. Retrieved from https:// www.marketwatch.com/press-release/global-surgical-chips-market2027-vision-penetration-of-technology-into-healthcare-industryboost-the-market-globally-market-research-future-2018-09-07

Martin B., \& Alexander, M. (2019, in press). The economic burden and practice restrictions associated with collaborative practice agreements: A national survey of advanced practice registered nurses. Journal of Nursing Regulation, 9(4).

Martin, P., Zindel, M. \& Nass, S. (Rapporteurs). (2018). Graduate medical education outcomes and metrics: Proceedings of a workshop. Washington DC: The National Academies of Sciences, Engineering, Medicine.

Martsolf, G. R., \& Kandrack, R. K. (2017). The Impact of establishing a full scope of practice for advanced practice registered nurses in the state of Indiana. RAND Corporation. Retrieved from https://www. rand.org/pubs/research_reports/RR1864.html

Mathioudakis, N., Jeun, R., Godwin, G., Perschke, A., Yalamanchi, S., Everett, E., ... Hill Golden, S. (2018). Development and implementation of a subcutaneous insulin clinical decision support tool for hospitalized patients. Journal of Diabetes Science and Technology. https:// doi.org/10.1177/1932296818798036

Mensik, J. (2017, Dec. 20). New York governor signs BSN in 10 into law for nurses. Retrieved from https://www.nurse.com/blog/2017/12/20/ new-york-governor-signs-bsn-in-10-into-law-for-nurses/

Microsoft Reporter. (2018). Using holograms to train nurses: Pearson and Microsoft launch mixed-reality curriculum. Retrieved from: https:// news.microsoft.com/en-gb/2018/01/22/using-holograms-trainnurses-pearson-microsoft-launch-mixed-reality-curriculum/

Miliard, M. (2018, August 14). IBM responds to recent Watson media coverage. Healthcare IT News. Retrieved from https://www. healthcareitnews.com/news/ibm-responds-recent-watson-mediacoverage

Moghe, S. (2016, October 14). Opioid history: From 'wonder drug' to abuse epidemic. CNN. Retrieved from https://www.cnn. com/2016/05/12/health/opioid-addiction-history/index.html

Murray, T. A. (2018). Nursing education: Our iceberg is melting. Journal of Nursing Education, 57(10), 575-576.

National Academies of Sciences, Engineering, and Medicine. (2018). Graduate medical education outcomes and metrics: Proceedings of a workshop. Washington DC: The National Academies Press.

National Association of Clinical Nurse Specialist. (2015). Press room: National Association of Clinical Nurse Specialists endorses requiring doctor of nursing practice degree for clinical nurse specialists. Retrieved from https://nacns.org/2015/07/national-association-ofclinical-nurse-specialists-endorses-requiring-doctor-of-nursingpractice-degree-for-clinical-nurse-specialists/
National Conference of State Legislatures (NCSL) (2017). The State of Occupational Licensing: Research, State Policies and Trends. National Council of State Legislatures. Retrieved from http://www.ncsl. org/Portals/1/HTML_LargeReports/occupationallicensing_final.htm

National Council of State Boards of Nursing. (2008). The Consensus model for APRN regulation: Licensure, accreditation, certification, education. Retrieved from https://www.ncsbn.org/Consensus_ Model_for_APRN_Regulation_July_2008.pdf

National Council of State Boards of Nursing. (2017). Member board profiles: Education. Retrieved from https://www.ncsbn.org/2017_ Education_MBPResponses.pdf

National Council of State Boards of Nursing. (2018a). Enhanced Nurse Licensure Compact (eNLC) implemented Jan. 19, 2018. Retrieved from https://ncsbn.org/11945.htm

National Council of State Boards of Nursing. (2018b). APRN consensus implementation status. Retrieved from https://www.ncsbn.org/5397. htm

National Council of State Boards of Nursing. (2018c). Nurse Licensure Compact (NLC). Retrieved from https://www.ncsbn.org/nurse-licensurecompact.htm

National Council of State Boards of Nursing. (2018d). The national nursing database: A profile of nursing licensure in the US. Retrieved from https://www.ncsbn.org/national-nursing-database.htm

National Council of State Boards of Nursing. (2018e). The NCSBN national nursing guidelines for medical marijuana. Journal of Nursing Regulation, 9(Suppl. 2), S5.

National Institute on Drug Abuse. (2018). Tobacco, Alcohol, Prescription Medication, and Other Substance Use (TAPS) tool. Retrieved from https://www.drugabuse.gov/taps/\#/

National League for Nursing. (2012). National League for Nursing fair testing guidelines for nursing education. Retrieved from http://www. nln.org/docs/default-source/advocacy-public-policy/fair-testingguidelines.pdf?sfvrsn $=0$

National League for Nursing. (2017). National League for Nursing fair testing guidelines for nursing education. Retrieved from: http:// www.nln.org/docs/default-source/advocacy-public-policy/fair-testingguidelines.pdf?sfvrsn=0.NLN faculty census survey. Retrieved from: http://www.nln.org/newsroom/nursing-education-statistics/nlnfaculty-census-survey-2016-2017

National Organization of Nurse Practitioner Faculties. (2018). The doctor of nursing practice degree: Entry to nurse practitioner practice by 2025. Retrieved from https://cdn.ymaws.com/www.nonpf.org/ resource/resmgr/dnp/v3_05.2018_NONPF_DNP_Stateme.pdf

National Registry of Emergency Medical Technicians. (2018). Recognition of EMS personnel licensure interstate compact. Retrieved from https://www.nremt.org/rwd/public/document/replica

Nebraska Department of Health and Human Services. (2018, January 8). DHHS launches additional enhancements to prescription drug monitoring program. [Press Release]. Retrieved from http://dhhs.ne.gov/ Pages/newsroom_2018_January_PDMP.aspx

Nevada State Board of Nursing. (2018). Apprentice nurse skills list. Retrieved from https://nevadanursingboard.org/education-andcontinuing-education/apprentice-nurse-skills-list/

New York State Nurses Association. (2018). Position statement on sexual harassment. Retrieved from https://www.nysna.org/position-statement-sexual-harassment\#.W74dwmhKiF4 
Nightingale College (2018, October 25). Will a BSN degree be mandatory for RNs? Find out all the nurses qualifications, laws \& requirements by state. Nightingale College. Retrieved from https:// nightingale.edu/blog/rn-bsn-requirements-by-state/

Noah, B., Keller, M. S., Mosadeghi, S., Stein, L. Johl, S., Delshad, S., Spiegel, B. M. R. (2018). Impact of remote patient monitoring on clinical outcomes: An updated meta-analysis of randomized controlled trials. npj Digital of Medicine. Retrieved from https://www.nature. com/articles/s41746-017-0002-4\#Sec20

North Carolina State Board of Dental Examiners v. Federal Trade Commission. (2015). 135 S. Ct. 1101.

Norton Healthcare. (2018). Student nurse apprenticeship program. Retrieved from https://nortonhealthcare.com/assets/documents/ careers/snap-application-flier-08202018.pdf

Nunn, Ryan (2016, June 21). Occupational Licensing and American Workers. Brookings. Retrieved from https://www.brookings.edu/ research/occupational-licensing-and-the-american-worker/

Occupational Licensing Board Antitrust Damages Relief and Reform Act of 2018, H.R. 6515, 115th Cong. (2018).

Odom-Maryon, T., Bailey, L.A., \& Amiri, S. (2018). The influences of nursing school characteristics on NCLEX-RN pass rates: A national study. Journal of Nursing Regulation, 9(3), 59-69.

Oermann, M. H. (2018). Another look at competencies and clinical evaluation: From 40 years ago. Nurse Educator, 43(4), 167.

Outtz, J. H. (1979). Predicting the success on state board examinations for blacks. The Journal of Nursing Education, 18(9), 35-40.

Peters, A. (2017, Oct. 31). Can blockchain disrupt health education, licensing, and credentialing? The Lancet Global Health Blog. Retrieved from http://globalhealth.thelancet.com/2017/10/31/can-blockchaindisrupt-health-education-licensing-and-credentialling

Pickham, D., Berte, N., Pihulic, M., Valdez, A., Mayer, B., \& Desai, M. (2018). Effect of a wearable patient sensor on care delivery for preventing pressure injuries in acutely ill adults: A pragmatic randomized clinical trial (LS-HAPI study). International Journal of Nursing Studies, 80, 12-19.

Pittman, P. (in press). The growth and performance of for-profit nursing programs. Journal of Nursing Regulation.

Protecting JOBs Act. (2018) S.B. 3065, 115th Cong.

PT Compact. (2017). What states are in the compact? Retrieved from http://ptcompact.org/ptc-states

Radley, D. C., McCarthy, D., \& Hayes, S. (2018). 2018 scorecard on state health system performance. The Commonwealth Fund. Retrieved from https://interactives.commonwealthfund.org/2018/state-scorecard/ files/Radley_State_Scorecard_2018_APPENDIX.pdf

Ronald, J. S. (1979). Computers \& undergraduate nursing education: A report on an experimental introductory course. The Journal of Nursing Education, 18(9), 4-9.

Rusch, L., Beiermann, T., Schoening, A. M., Slone, C., Flott, B., Manz, J. \& Miller, J. (2018). Defining roles and expectations for faculty, nurses, and students in a dedicated education unit. Nurse Educator, 43(1), 14-17.

S.B. 147, 2018 Reg. Sess. (Utah. 2018).

S.B. 18-022, 71st General Assembly, 2nd Reg. Sess. (Colo. 2018).

S.B. 225, 2018 Reg. Sess. (Ind. 2018).

S.B. 2298, 29th Legislature, 2018 Reg. Sess. (Hawaii. 2018).

S.B. 2526. 2018 Reg. Sess. (Miss. 2018).

S.B. 2646, 29th, Legislature, 2018 Reg. Sess. (Hawaii. 2018).
S.B. 2777, 100th General Assembly, 2018 Reg. Sess. (Ill. 2018).

S.B. 28, 2018 Reg. Sess. (Ind. 2018).

S.B. 302, 122nd Session, 2017-2018 Reg. Sess. (S.C. 2018).

S.B. 42, 64th Legislature, 2018 Reg. Sess. (Wyo. 2018).

S.B. 522, 2018 Reg. Sess. (Md. 2018).

S.B. 6768, 2017-2018 Reg. Sess. (N.Y. 2017).

Sagonowsky, E. (2017, November 16). Lilly used nursing services as kickbacks to boost insulin prescriptions, lawsuit claims. FiercePharma. Retrieved from https://www.fiercepharma.com/legal/eli-lilly-underfire-newly-unsealed-lawsuit-alleging-illegal-marketing

Schlachta-Fairchild L, Elfrink V., \& Deickman, A. (2008). Patient safety, telenursing, and telehealth. In R. G. Hughes (Ed.), Patient safety and quality: An evidence-based handbook for nurses. Rockville, MD: Agency for Healthcare Research and Quality. Retrieved from https://www. ncbi.nlm.nih.gov/books/NBK2687/

Scott-Clayton, Judith. (2018, January 11). The looming student loan default crisis is worse than we thought. Brookings. Retrieved from https://www.brookings.edu/research/the-looming-student-loandefault-crisis-is-worse-than-we-thought/

Scutti, S. (2017, November 7). Experimental technology can 'smell' disease on your breath. CNN. Retrieved from https://www.cnn. com/2017/11/07/health/na-nose-disease-smell-technology/index. html

Seldomridge, L. A. \& Walsh, C.M. (2018). Waging the war on clinical grade inflation: The ongoing quest. Nurse Educator, 43(4), 178-182.

Silver-Greenberg, J., Cowley, S., \& Kitroeff, N. (2017, November 18). When unpaid student loan bills mean you can no longer work. The New York Times. Retrieved from https://www.nytimes. com/2017/11/18/business/student-loans-licenses.html

Silverman, E., \& Weintraub, K. (2018, October 2). Caregivers or marketers? Nurses paid by drug companies facing scrutiny as whistleblower lawsuits mount. Stat. Retrieved from https://www.statnews. com/2018/10/02/nurse-educators-humira-whistleblower-lawsuits/

Simmons University. (2014, November 13). History of nurse practitioners in the United Sates [Slide Show]. Nursing@Simmons. Retrieved from https://onlinenursing.simmons.edu/nursing-blog/history-nursepractitioners/

Siwicki, B. (2018). Telemedicine innovation: Rural health system keeping more people alive at lower costs. Healthcare IT News. Retrieved from https://www.healthcareitnews.com/news/telemedicine-innovationrural-health-system-keeping-more-people-alive-lower-costs

Smiley, R. A., Lauer, P., Bienemy, C., Berg, J. G., Shireman, E., Reneau, K. A., \& Alexander, M. (2018). The 2017 national nursing workforce survey. Journal of Nursing Regulation, 9(Suppl. 3), S1-S88.

Smith. A. A. (2018). From nursing apprenticeships to bachelor's degrees. Inside HigherEd. Retrieved from https://www.insidehighered.com/ news/2018/09/06/new-report-encourages-apprenticeships-nursingpathway-bsn-degrees

Sonenberg A., \& Knepper, H. J. (2017). Considering disparities: How do nurse practitioner regulatory policies, access to care, and health outcomes vary across four states? Nursing Outlook, 65(2), 143-153.

Spector, N. \& Alexander, M. (2006). Exit exams from a regulatory perspective. Journal of Nursing Education, 45(8), 291-292.

Spector, N., Hooper, J. I., Silvestre, J. \& Qian, H. (2018). Board of nursing approval of registered nursing education programs. Journal of Nursing Regulation, 8(4), 22-31. 
Spector, S., Frederick, W. (1952). Occupational licensing legislation in the states. Council of State Governments. Retrieved from https://hdl.handle. net/2027/mdp.39015009044218.

Spetz, J. (2018) Projections of progress toward the $80 \%$ bachelor of science in nursing recommendation and strategies to accelerate change. Nursing Outlook, 66(4), 394-400.

State of California v. AbbVie, No. RG18893169 (Superior Court of the State of California County of Alameda, 2018).

Stewart, D. M., \& Mueller, C. A. (2018). Substance use disorder among nurses: A curriculum improvement initiative. Nurse Educator, 43(3), $132-135$.

Substance Abuse and Mental Health Services Administration. (2018). Reports and detailed tables from the 2017 National Survey on Drug Use and Health (NSDUH). Retrieved from https://www.samhsa.gov/ data/nsduh/reports-detailed-tables-2017-NSDUH

Support for Patients and Communities Act. (2018). H.R. 6, 115th Cong.

Syrop, J. (2017, November 21). Lawsuit alleges Eli Lilly used kickbacks to increase use of its insulin products. The Center for Biosimilars.

Retrieved from https://www.centerforbiosimilars.com/news/lawsuitalleges-eli-lilly-used-kickbacks-to-increase-use-of-its-insulinproducts

Thew, Jennifer (2018, January 4). 'BSN in 10’ Becomes Law in New York. Nurse Leader Insider. Retrieved from https://www.healthleadersmedia. com/nursing/bsn-10-becomes-law-new-york

Thompson, L. M., Zablotska, L. B., Chen, J., Jong, S., Alkon, A., Lee, S., Vlahov, D. (2018). Development of quantitative research skills competencies to improve doctor of philosophy nursing student training. Journal of Nursing Education, 57(8), 483-488.

Thomsen, Sarah (2018, December 6). Target 2 Investigates: State studies deregulating occupational licenses. Action News 2. Retrieved from https://www.wbay.com/content/news/Target-2-Investigates-Statestudies-deregulating-occupational-licenses-502108451.html

Thornton, R and Timmons, E. (2015, May). The de-licensing of occupations in the United States. Monthly Labor Review, U.S. Bureau of Labor Statistics. Retrieved from https://doi.org/10.21916/mlr.2015.13.

Townley, C. and Dorr, H. (2017). Integrating Substance Use Disorder Treatment and Primary Care. National Academy for State Health Policy, February 2017. Retrieved from https://nashp.org/wp-content/ uploads/2017/02/Primary-Care-Integration-Brief.pdf

Traczynski, J., \& Udalova, V. (2018). Nurse practitioner independence, health care utilization, and health outcomes. Journal of Health Economics, 58, 90-109.

Trossman, Susan (2008, November). BSN in ten. American Nurse Today, 3(11). Retrieved from https://www.americannursetoday.com/bsn-inten/

U.S. Bureau of Labor Statistics. (2018f). Occupational Outlook Handbook. Retrieved from https://www.bls.gov/ooh/healthcare/nursingassistants.htm

U.S. Bureau of Labor Statistics. (2018g). Occupational Outlook Handbook. Retrieved from https://www.bls.gov/ooh/healthcare/homehealth-aides-and-personal-care-aides.htm

U.S. Bureau of Labor Statistics. (2018h). Occupational Outlook Handbook. Retrieved from https://www.bls.gov/ooh/community-andsocial-service/health-educators.htm

U.S. Bureau of Labor Statistics. (2018a). Occupational employment statistics. Retrieved from https://www.bls.gov/oes/2016/may/oes291141. htm
U.S. Bureau of Labor Statistics. (2018b). Occupational employment statistics. Retrieved from https://www.bls.gov/oes/2017/may/oes292061. htm

U.S. Bureau of Labor Statistics. (2018c). Occupational Employment Statistics. Retrieved from https://www.bls.gov/oes/2017/may/ oes211094.htm

U.S. Bureau of Labor Statistics. (2018d). Occupational Employment Statistics. Retrieved from https://www.bls.gov/oes/2017/may/ oes311014.htm

U.S. Bureau of Labor Statistics. (2018e). Occupational Employment Statistics. Retrieved from https://www.bls.gov/oes/2017/may/ oes311011.htm

U.S. Census Bureau. (1979). Statistical Abstract of the United States: 1979. https://www.census.gov/library/publications/1979/compendia/ statab/100ed.html

U.S. Census Bureau. (2018a). Annual estimates of the resident population for the United States, regions, states, and Puerto Rico: July 1, 2017. Retrieved from https://www.census.gov/data/tables/2017/demo/ popest/state-total.html

U.S. Census Bureau. (2018b). National population by characteristics: 2010-2017. Retrieved from https://www.census.gov/data/ tables/2017/demo/popest/nation-detail.html

U.S. Department of Health and Human Services Health Resources Services Administration. (2010). HRSA's 2010 National Sample Survey of Registered Nurses.

U.S. Department of Health and Human Services. (1980). Health, United States, 1980. https://www.cdc.gov/nchs/data/hus/hus80acc.pdf

U.S. Department of Labor. (2017, Jan. 12). U.S. Labor Department awards $\$ 7.5 \mathrm{M}$ to fund research for improving geographic mobility for workers in licensed occupations. Retrieved from https://www.dol.gov/ newsroom/releases/eta/eta20170112-0

U.S. Department of Labor. (2018a). Apprenticeship nursing career lattice program. Retrieved from https://www.doleta.gov/OA/cael.cfm THIS $\mathrm{ONE}$ is on $\mathrm{S} 13$

U.S. Department of Labor. (2018b, June 25). U.S. Department of Labor awards $\$ 7$ million to states to support occupational licensing reform. Retrieved from https://www.dol.gov/newsroom/releases/eta/ eta20180625 This is on S20, abbreviated to (DOL, 2018)

U.S. Department of Veteran Affairs. (2018, May 11). VA expands telehealth by allowing health care providers to treat patients across state lines. Retrieved from https://www.va.gov/opa/pressrel/pressrelease. cfm? id $=4054$

Veterans Affairs Mission Act of 2018. (2018) S.B. 2372, 115th Cong.

Volkert, D. \& Johnston, H. (2018). Unique issues of DNP students: A content analysis. Nursing Education Perspectives, 39(5), 280-284.

Williams, R. (2018, April 12). Connecticut collaborating on best practices for occupational licensing. Retrieved from http://knowledgecenter. csg.org/kc/content/connecticut-collaborating-best-practicesoccupational-licensing

World Health Organization (WHO). 2016. Global strategic directions for strengthening nursing and midwifery 2016-2020. Retrieved from: https://www.who.int/hrh/nursing_midwifery/global-strategicmidwifery2016-2020.pdf?ua $=1$

World Health Organization. (2018a). Ebola situation reports: Democratic Republic of the Congo. Retrieved from https://www.who.int/ebola/ situation-reports/drc-2018/en/ 
World Health Organization. (September, 2018b). Risk communication and community engagement preparedness and readiness framework: Ebola response in the Democratic Republic of Congo in North Kivu. Retrieved from http://apps.who.int/iris/bitstream/handle/ 10665/275389/9789241514828-eng.pdf?ua = 1

Wozney, L., McGrath, P. J., Gehring, N. D., Bennett, K., Huguet, A., Hartling, L., ... Newton, A. S. (2018). eMental healthcare technologies for anxiety and depression in childhood and adolescence: Systematic review of studies reporting implementation outcomes. JMIR Mental Health, 5(2). https://doi.org/10.2196/mental.9655
Xue, Y., Kannan, V., Greener, E., Smith, J. A., Brasch, J., Johnson, B. A., \& Spetz, J. (2018). Full scope-of-practice regulation is associated with higher supply of nurse practitioners in rural and primary care health professional shortage counties. Journal of Nursing Regulation, $8(4), 5-13$. 


\section{Appendices}

\section{APPENDIX A}

\section{Board of Nursing Position and Advisory Statements}

A review of position/practice statements, clinical practice advisories, advisory/declaratory rulings, advisory opinions, and interpretive guidelines developed by boards of nursing (BONs) was conducted. These guidance documents reflect BON decisions regarding specific nursing practice concerns and provide direction to practicing nurses. BONs can review and update their existing guidance documents in anticipation of emerging issues and trends that may affect them in the upcoming year.

Ten states (Alaska, Arizona, Kentucky, Nebraska, New Hampshire, North Dakota, Ohio, Oklahoma, Oregon, and Texas) adopted and/or revised statements/opinions related to the administration of sedation, analgesia, and/or anesthesia. Eight states (Alaska, Florida, Kentucky, North Carolina, North Dakota, Oregon, South Carolina, and South Dakota) approved or revised statements/positions on cosmetic/aesthetic/dermatologic procedures. Delegation was another common theme, with six states (Kentucky, North Carolina, Oregon, South Carolina, Texas, and West Virginia) approving related statements/positions

The following is a list of the position/practice statements, clinical practice advisories, advisory/declaratory rulings, advisory opinions, and interpretive guidelines issued or revised by boards of nursing during September 2017 through September 2018:

\section{Alaska}

- Adopted the following advisory opinions: Newborn Circumcision Procedures, Board Governance Policies, Neuro Modulator Injections for Cosmetic Purposes: Registered Nurses \& Licensed Practical Nurses, Nitrous Oxide Use in the Pediatric Population, Registered Nurse Role in Self-administered Nitrous Oxide Analgesia in the Intrapartum and Immediate Postpartum Period, Registered Nurse Administration of Nitrous Oxide for Minimal Sedation and/or Pain Management for Adult Patients, CDC Opioid Prescribing Guidelines

\section{Arizona}

- Revised the following advisory opinions: Administration of tPA and DNase via Pigtail or ChestTube $(<15 \mathrm{Fr})$ for Pleural Effusion/Empyema, Amniotomy/Fetal Spiral Electrodes, Anesthetic Agents Administered by Registered Nurses for Limited Purposes: Airway Management, Advanced Practice Registered Nursing Programs Clinicals in Arizona by Out-of-State Programs, Blood Cell Salvage: The Role of the Registered Nurse, Cardiac Electrophysiology Related Procedures, External Ventricular Drain Management, Cerebral Spinal Fluid Sampling, and Line Flushing, Intubation: Endotracheal, and the Use of Advanced Airway Devices:The Role of the Registered Nurse, Local Anesthetic Agents Infiltration: Role of the Nurse, Preceptorship for Students in Pre-Licensure Programs, Prescription Medication Renewals Using Nursing
Protocol in an Ambulatory Setting, Subcutaneous Infusion, Ultrasounds: Limited Obstetric, Gynecologic, and Reproductive, Ventilator Care by Licensed Practical Nurses, Wound Care: Role of the RN and LPN

Arkansas

- Revised the following position statement: School Nurse Roles and Responsibilities

Florida

- Adopted the following declaratory statements: Injection of Dermal Fillers and Botulinum Toxin, Registered Nurses' procedural roles in the placement of a Percutaneous Endoscopic, Lipo LaserTreatment (2017), Services to Residents of Nursing/Rehabilitation Center, Manual Lymphatic Drainage, Bravo Ph Monitoring System Without the Physical Presence of Physician, Lipo LaserTreatment (2018), Myofascial Release of the Soft Tissues of the Pelvic Floor

Illinois

- Posted the following: Notice Regarding Changes to APRN Provisions in the Nurse Practice Act

Kansas

- Adopted the following guideline/position statement: Joint Policy Statement on the Kansas Board of Healing Arts, Nursing and Pharmacy on the Use of Controlled Substances for theTreatment of Chronic Pain

\section{Kentucky}

- Revised the following advisory opinions: Role of the RN/ LPN in Spinal Screening for Detection of Common Abnormal/Curvatures of the Spine, Scope of Nursing Practice in Gynecological Cancer Detection, Recommended Course Content Intravenous (IV)Therapy for Registered Nurses and Licensed Practical Nurses, Role of Nurses in the Administration of Medication Per Intraspinal Routes, Performance of Aterial Puncture by Registered Nurses, Role of Nurses in Superficial Wound Closure, Role of the Registered Nurse First Assistant, Wound Assessment, Staging, and Treatment by Nurses, Roles of Nurses in the Care of Prenatal and Intrapartum Patients, Insertion and Removal of Nasogastric Tubes and Reinsertion of Percutaneous Endoscopic Gastronomy (PEG)Tubes, Roles of Nurses in Psychiatric-Mental Health Nursing Practice, Roles of Nurses in the Implementation of Patient Care Orders, Roles of Nurses in the Supervision and Delegation of Nursing Acts to Unlicensed Personnel, Roles of Nurses in the Administration of Medication Via Various Routes, Roles of Nurses in the Administration of "PRN" Medication and Placebos, Employment of Nursing Students as Nursing Personnel Using Either an Academic or a "Nurse Extern" Service Model, Responsibility and Accountability of Nurses for Patient Care Assignments and Nursing Care Delivery, Roles of Registered Nurses in Invasive Cardiac Procedures, Role of Nurses and Techni- 
cians in Dialysis, Role of Nurses Who Provide “Private Duty" Nursing, The Application and Removal of a Cast by Nurses and Closed Reduction of a Fracture by Advance Practice Registered Nurses, Patient Abandonment by Nurses, Placement of Central Lines by Nurses, Roles of Nurses in the Performance of Advanced Life Support and Deliver of Emergency Medical Care via Ambulance Services, Components of Licensed Practical Nursing Practice, Roles of Nurses in Endoscopic Procedures, Cardiopulmonary/Respiratory Nursing, Nursing School Practice, Removal of Arterial and Venous Access Devices (Sheaths) and Use of Mechanical Compression Devices by Nurses, Procedural Sedation and Analgesia, Roles of Nurses in the Delegation of Tasks to Paramedics in a Hospital Emergency Department, Roles of Nurses in Maintaining Confidentiality of Patient Information, Cosmetic and Dermatological Procedures by Nurses, Resuscitation Orders, Pronouncement of Death and Death Certificates, Role of the Advanced Practice Registered Nurse in the Prescribing of Medications to Self and/or Family, Scope of Registered Nursing Practice in the Deactivation of Internal Defibrillator, Social Media for Nurses, RN/LPN Scope of Practice Determination Guidelines

- Approved the following scope of practice determination guidelines and decision tree for delegation to UAP: RN/ LPN Scope of Practice Determination Guidelines, APRN Scope of Practice Decision Making Model, DecisionTree for Delegation to Unlicensed Assistive Personnel

- Posted the following practice opinions: Scope of Practice of Registered Nurses in the Delegation of Medication Administration of Klonopin ${ }^{\mathrm{TM}}$ (Clonazepam) Wafers for Seizure Management to Unlicensed Assistive Personnel, Scope of Practice of the APRNs (CRNAs \& CNMs) Role Designation/Population Focus Performing Sports Physicals, Scope of Practice of the APRN CRNA in the Independent Practice of Cosmetic and Dermatologic Procedures, Scope of Practice of the Ketamine Clinics for Chronic Pain/PTSD

Louisiana

- Adopted the following declaratory statement:The Registered Nurse Delegating toTrained, Unlicensed School Employees, the Administration of Medications During LifeThreatening Situations

\section{Massachusetts}

- Issued the following advisory rulings: Licensure required to practice nursing

- Revised the following advisory rulings: APRN prescriptive authority in federal entities; Nursing practice and cardiopulmonary resuscitation; Foot care; Accepting, verifying, transcribing and implementing prescriber orders

Minnesota

- Reaffirmed the following: Statement of accountability for utilization of integrative therapies in nursing practice

\section{Nebraska}

- Adopted the following advisory opinions: Nonsurgical wound closure; Team-based nursing care services; Verbal orders; Wound debridement

- Revised the following advisory opinions: Patient abandonment; Casting; Nurse's accountability to perform cardiopulmonary resuscitation; Deployment of vascular closure devices; Procedural sedation; Safety to practice: Fitness to practice; Sub-anesthetic ketamine

New Hampshire

- Approved the following position statements and advisories: Scope of licensed nursing assistant (LNA) practice; Continuous positive airway pressure, bi-level positive airway pressure; Complementary and alternative practice modalities and the New Hampshire scope of practice; Administration of palliative sedation

- Revised the following position statements and advisories: LPN scope of practice; Role of the RN and LPN in telehealth nursing

- Discontinued the following advisory: Home nurses with medications in their possession while in the role of home health nurse

\section{North Carolina}

- Revised the following position statements: Adult care settings; Cosmetic/aesthetic dermatological procedures; Delegation of medication administration to UAP; Delegation: Nurse aide II credentialed as EMT-I/P; LPN scope of practice - clarification; Office practice setting; Out-ofstate nurses practicing in North Carolina for a limited period of time; RN scope of practice - clarification; Unlicensed new graduate nurse - role; Wound role

\section{North Dakota}

- Adopted the following guidance document: Role of the nurse in sedation/analgesia

- Approved the following interpretive statements: RN scope of practice and prescribed injectable aesthetic agents; North Dakota Association of Nurse Anesthetists interpretive statement for dry needling by CRNAs in North Dakota

Ohio

- Approved the following interpretive guideline: RN insertion of an internal jugular central venous catheter in adults

- Reapproved the following interpretive guidelines: RN filling and unfilling a patient's gastric band; RN performance of conservative sharp wound debridement; RN care of patients receiving intravenous moderate sedation for medical and/or surgical procedures; RN role in emergent intubation performed by an authorized provider; RN utilization of the Sapiens TCS or other comparable device to confirm peripherally inserted central catheter tip placement; $\mathrm{RN}$ role in the care of patients undergoing exercise cardiac stress testing; $\mathrm{RN}$ role in the care of patients receiving intravitreal injectable medications 
Oklahoma

- Revised the following position statements and guidelines: CRNA inclusionary formulary; Decision-making model for scope of nursing practice decisions: Determining APRN, RN and LPN scope of practice guidelines; APRN certification examinations approved by the Oklahoma BON; Rapid sequence intubation guidelines - Medication administration by RNs; Refresher course policy; $\mathrm{RN}$ administering, managing and monitoring non-obstetrical patients receiving analgesia/anesthesia by catheter techniques (epidural, patient controlled epidural analgesia [PCEA] and intrathecal catheters) guidelines; RN monitoring obstetrical patients receiving analgesia/anesthesia by catheter techniques (epidural, PCEA and intrathecal catheters) guidelines

\section{Oregon}

- Approved the following interpretive statement: APRN scope of practice and the care of the transgender patient

- Formatted/approved the following interpretive statements: RN who participates in cosmetic procedures; "Delegation process" and "Assignment and supervision"; Provision of foot care by the RN and the LPN; Role of the $\mathrm{RN}$ in performing medical screening examinations under the Emergency MedicalTreatment and Active Labor Act; RN who performs sexual assault examinations; $\mathrm{RN}$ who administers a pharmacologic agent to a client to achieve moderate or deep sedation

- Reviewed the following interpretive statements: Fitness to practice: Evaluation of applicants; Fitness to practice: Substance use disorder

- Revised the following interpretive statements: Fitness to practice: Failure to disclose, lying, or falsification of applications; Fitness to practice: Sexual misconduct; Scope of practice decision making guidelines for all licensed nurses

\section{South Carolina}

- Approved the following advisory opinions: Joint advisory opinion of the South Carolina State Boards of Dentistry, Medical Examiners and Nursing regarding the administration of neuromodulators including Botox; Revised joint advisory opinion issued by the South Carolina Boards of Medical Examiners, Nursing and Pharmacy regarding over-the-counter medications and herbal supplements in schools

- Formulated the following position statement: Use of simulation in pre-licensure nursing programs

- Revised the following position statement: Recommended age parameters for the APRN practicing in South Carolina; Delegation of nursing care tasks to unlicensed assistive personnel (UAP)

- Reviewed the following position statement: Assisting with medications; Patient abandonment; Scope of practice decision tree

\section{South Dakota}

- Approved the following: APRN practice guidelines

- Revised the following advisory opinions: Dermatological procedures
Tennessee

- Approved the following position statement: Registered nurse role in physical assessment and determination of active labor

Texas

- Adopted the following position statement: Workplace violence

- Revised the following position statements: Nurses carrying out orders from physician assistants; Role of the LVN in the pronouncement of death; LVNs engaging in IV therapy, venipuncture, or PICC lines; Educational mobility; Nurses with responsibility for initiating physician standing orders; Board rules associated with alleged patient "abandonment"; Role of LVNs \& RNs in management and/or administration of medications via epidural or intrathecal catheter routes; Role of the nurse in moderate sedation; Performance of laser therapy by RNs or LVNs; Continuing education: Limitations for expanding scope of practice; Delegated medical acts; Use of American Psychiatric Association diagnoses by LVNs, RNs, or APRNs; Role of LVNs and RNs in school health; Duty of a nurse in any practice setting; Board's jurisdiction over a nurse's practice in any role and use of the nursing title; Development of nursing education programs; Texas Board of Nursing/Board of Pharmacy, Joint Position Statement, Medication errors; Nurses carrying out orders from APRNs; Nurses carrying out orders from pharmacists for drug therapy management; RNs in the management of an unwitnessed arrest in a resident in a long term care facility; APRNs providing medical aspects of care for individuals with whom there is a close personal relationship; Use of complementary modalities by the LVN or RN; Nurses engaging in reinsertion of permanently placed feeding tubes; Administration of medication \& treatments by LVNs; LVN scope of practice; RN scope of practice; Professional boundaries including use of social media by nurses

\section{Vermont}

- Revised the following position statements: Fitness for work; Role of the RN in obtaining informed consent for a treatment or procedure; Licensed nurse assistant (LNA) scope of practice; Role of the LPN in patient assessment and triage; APRN/RN/LPN scope of practice and decision tree

\section{Virginia}

- Revised the following guidance documents: Medication administration training curriculum; Guidance statement by board regarding peripherally inserted central catheters

\section{Washington}

- Adopted the following advisory opinion: Compounding medications by LPNs, RNs, and Advanced Registered Nurse Practitioners (ARNPs); Medical acupuncture: Scope of practice for ARNPs 
West Virginia

- Revised the following position statements: Administration of anesthetic agents by RNs; Delegation of medication administration by an APRN

Wyoming

- Approved the following advisory opinions: Guidance for the administration of medication in alternate settings; Conversion of educational hours

- Revised the following advisory opinions: LPN and RN scope of practice; Role of nurses in superficial wound closure and post care; Telephonic \& electronic nursing 


\section{APPENDIX B}

\section{Center for Regulatory Excellence Research Grants}

The NCSBN's Center for Regulatory Excellence Grant Program funds research projects with grants up to $\$ 300,000$ that can have measurable impact on nursing regulation. Research priorities include but are not limited to: patient safety, scope of practice, nursing education, continued competence, discipline and alternatives to discipline, nurse mobility, and national and international regulatory issues. Grant recipients and projects for 2018 are listed in the table below.

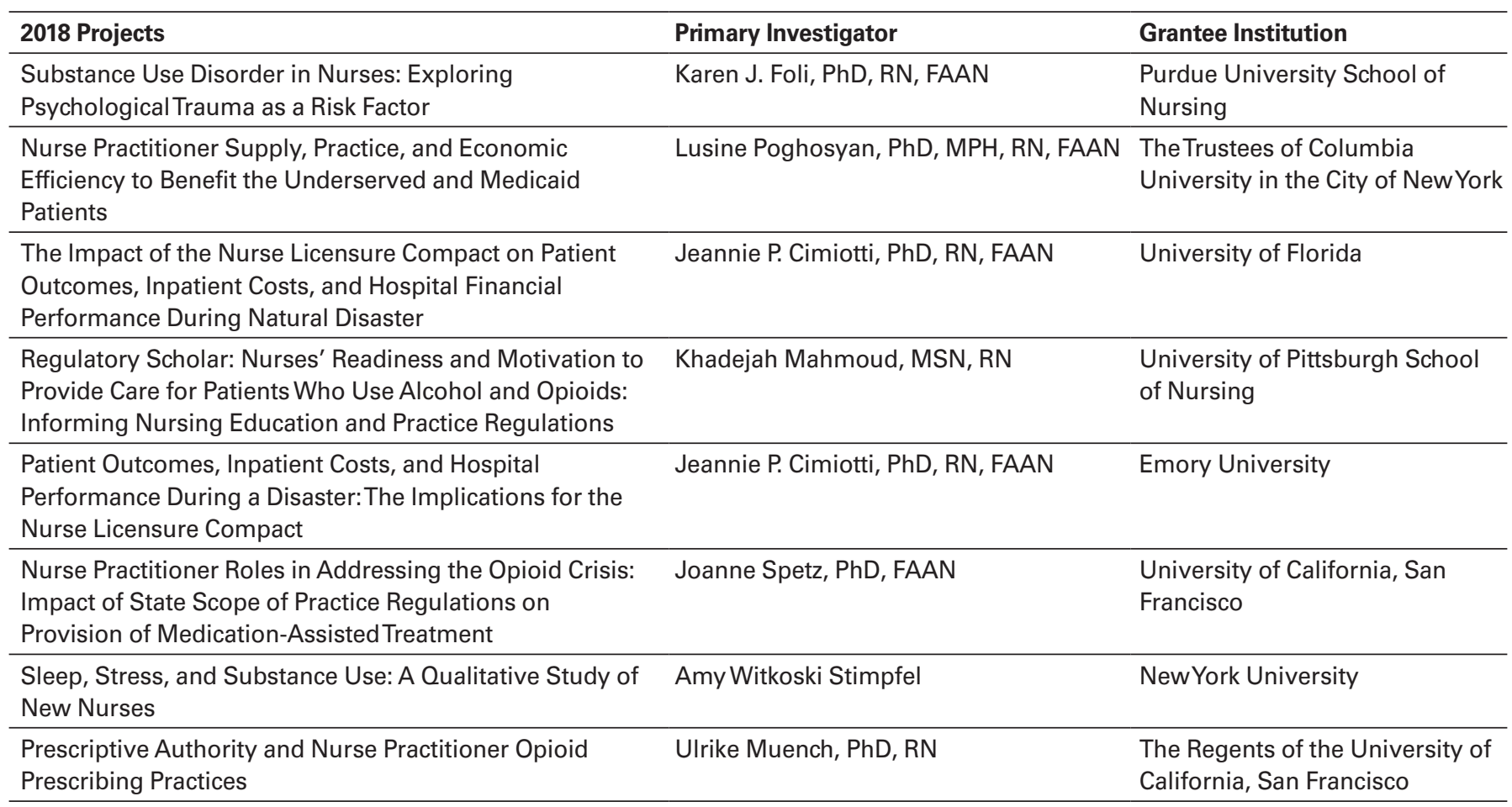

